ORNL- -6620

DE91 $0056 \angle 6$

ORNL-6620

\title{
ELECTRICITY PRICING \\ AS A DEMAND-SIDE MANAGEMENT STRATEGY: WESTERN LESSONS FOR DEVELOPING COUNTRIES
}

\author{
Lawrence J. Hill \\ Energy and Economic Analysis Section \\ Energy Division \\ DATE PUBLISHED: DECEMBER 1990
}

Prepared for

Office of Energy, Science, and Technology Bureau

U.S. AGENCY FOR INTERNATIONAL DEVELOPMENT

under Interagency Agreement No. DOE 1637-1637-A1

Prepared by

OAK RIDGE, NATIONAL LAWORATORY

Oak Ridge, Tennessee 37831

Managed by

MARTIN MARIETTA ENERGY SYSTEMS, INC.

for the

U.S. DEPARTMENT OF ENERGY

under Contract No. DE-AC05-84OR2140 


\section{CONTENTS}

LIST OF FIGURES AND TABLES $\ldots \ldots \ldots \ldots \ldots \ldots \ldots \ldots \ldots \ldots \ldots$

ACKNOWLEDGMENTS $\ldots \ldots \ldots \ldots \ldots \ldots \ldots \ldots \ldots \ldots \ldots \ldots$ vii

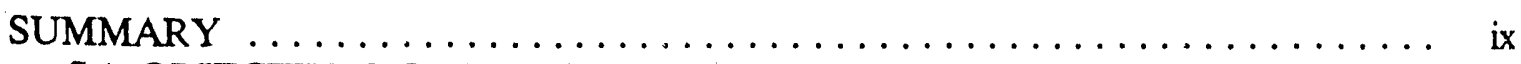

S.1. OBJECTTVES OF THE STUDY $\ldots \ldots \ldots \ldots \ldots \ldots \ldots \ldots \ldots \ldots \ldots \ldots \ldots \ldots \ldots$

S.2. OVERVIEW .......................

S.3. TOU RATES AND LOW-VOLTAGE USERS $\ldots \ldots \ldots \ldots \ldots \ldots \ldots \ldots$ xi

S.4. TOU RATES AND HIGH-VOLTAGE USERS $\ldots \ldots \ldots \ldots \ldots \ldots \ldots$ xiii

S.5. FROM STATIC TO DYNAMIC TOU TARIFFS $\ldots \ldots \ldots \ldots \ldots \ldots \ldots$ xiv

S.6. RELEVANCE FOR DEVELOPING COUNTRIES $\ldots \ldots \ldots \ldots \ldots \ldots \ldots$ xv

1. INTRODUCTION TO DEMAND-SIDE MANAGEMENT (DSM) $\ldots \ldots \ldots \ldots 1$

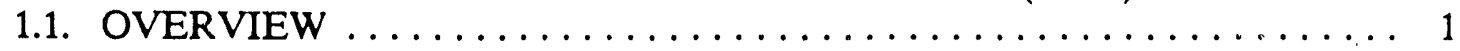

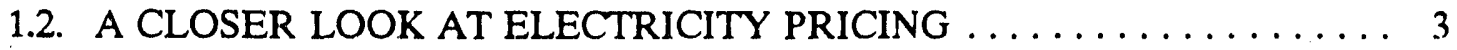

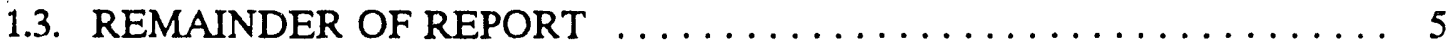

2. RESPONSE TO TOU RATES: THE MEASUREMENT PROBLEM $\ldots \ldots \ldots .7$

3. RESPONSE TO TOU TARIFFS: LOW-VOLTAGE USERS ......... 11

3.1. INDIVIDUAL TOD EXPERIMENTS $\ldots \ldots \ldots \ldots \ldots \ldots \ldots \ldots \ldots \ldots$

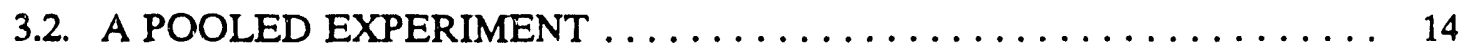

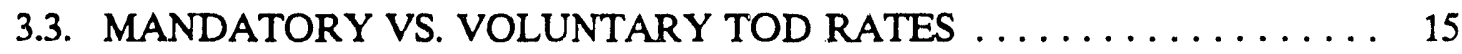

3.4. USING PRICES TO IMPLEMENT OTHER DSM PROGRAMS . . . . . . 17

4. RESPONSE TO TOU RATES: HIGH-VOLTAGE USERS . . . . . . . . 21

4.1. AGGREGATE RESPONSE TO TOD RATES ACRiSSS INDUSTRIES . . 23

4.2. RESPONSE TO TOD RATES BY INDIVIDUAL INDUSTRIES . . . . . 26

4.3. THE EFFECT OF INTERRUPTIBLE/CURTAILABLE TARIFFS $\ldots \ldots .29$

5. COST-EFFECTIVENESS OF TOD PRICING $\ldots \ldots \ldots \ldots \ldots \ldots \ldots \ldots \ldots$

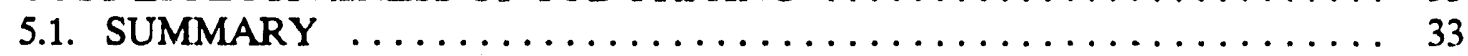

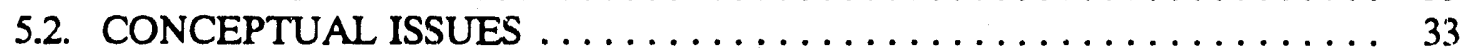

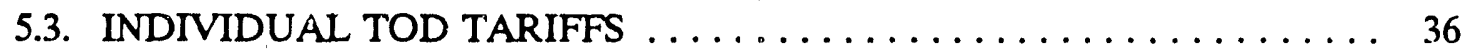

6. EMERGING TECHNOLOGY AND FUTURE DIRECTIONS

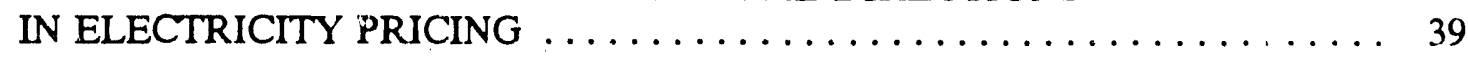

BIBLIOGRAPHY $\ldots \ldots \ldots \ldots \ldots \ldots \ldots \ldots \ldots \ldots \ldots \ldots \ldots \ldots \ldots$

iii $/$ iv 


\section{LIST OF FIGURES AND TABLES}

Figure

1 Hypothetical Load Curve Before and After Indtroduction of TOD Rates $\ldots 7$

2 Hypothetical Load Curve different System Peaks .............. 9

$3 \quad$ Load Curves for a French Cement Plant ................. 27

$4 \quad$ Load Curves for a French Petroleum Pipeline $\ldots \ldots \ldots \ldots \ldots \ldots \ldots$

Table

1 Implemented Electricity Tariffs in the United States

U.S. Investor-Owned Utilities Survey Results 1983 and 1986 . . . . . . . . 4

2 Implemented Electricity Tariffs in the U.S. Residential Sector Survey Results

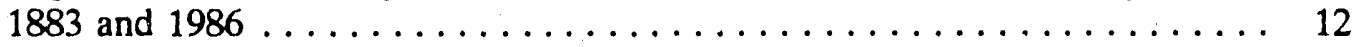

3 Summary of Five U.S. Residential TOD Pricing Experiments . . . . . . . 13

4 Customer Response to U.S. Residential TOD Rates Summer Months Different Appliance and Weather Scenarios .............. 16

5 Percent of Residential Electricity Consumption in Off-Peak Hours by Type of Heating System England and Wales $1975 \ldots \ldots \ldots \ldots \ldots$. . . . 18

6 Implemented Electricity Tariffs in the U.S. Industrial Sector Survey Results .......................... 22

7 Summary of Four Studies of U.S. Response to High-Voltage TOU Rates . . 24

8 Change in Relative Loads Introduction of Tou Rates U.S. High-Voltage Corsumers . . . . . . . . . . . . . . . . 25

9 Customer Response to Interruptible/Curtailable Rates Ten U.S. Utilities . . 30

10 Summary of Credited Relief under U.S. Interruptible/Curtailable Rates

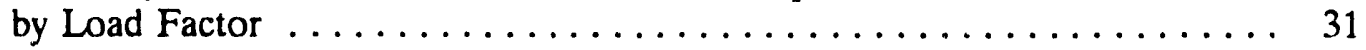

11 Central Illinois Light Company Comparison of Discounted Net

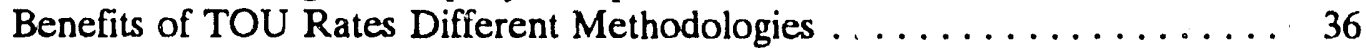

12 Summary of Four Cost-Benefit Studies U.S. Residential TOD Tariffs . . . 37

13 Design of Three U.S. Real-Tir. 2 Pricing Experiments $\ldots \ldots \ldots \ldots \ldots \ldots 40$

$$
\text { vivi }
$$




\section{ACKNOWLEDGMENTS}

This study is an expanded version of a paper prepared for the PACER (Project to Accelerate the Commercialization of Energy Research) Conference in New Delhi, India in April 1990. The financial support of the Office of Energy, U.S. Agency for International Development and USAID New Delhi, two sponsors of the conference, is greatly appreciated. Also, the comments of Tom Wilbanks, Bob Perlack, and Colleen Rizy on an earlier version of the study are much appreciated. 


\section{SUMMARY \\ ELECTRICITY PRICING \\ AS A DEMAND-SIDE MANAGEMENT STRATEGY: WESTERN LESSONS FOR DEVELOPING COUNTRIES}

Lawrence J. Hill

\section{S.1. OBJECTIVES OF THE STUDY}

Electric utilities in the Western world have increasingly realized that load commitments can be met not only by constructing new generating plants but also by influencing electricity deniand. This demand-side management (DSM) process requires that electric utilities promote measures on the customer's side of the meter to directly or indirectly influence electricity consumption to meet desired load objectives. An important demand-side option to achieve these load objectives is innovative electricity pricing, both by itself and as a financial incentive for other demand-side measures.

This study explores electricity pricing as a DSM strategy, addressing four questions in the process:

1. What is the Western experience with DSM in general and electricity pricing in particular?

2. Do innovative pricing strategies alter the amount and pattern of electricity consumption?

3. Do the benefits of these pricing strategies outweigh the costs of implementation?

4. What are future directions in electricity pricing?

Although DSM can be used to promote increases in electricity consumption for electric utilities with excess capacity as well as to slow demand growth for capacity-short utilities, emphasis here is placed on the latter. The discussion should be especially useful for electric utilities in developing countries that are exploring alternatives to capacity expansion to meet current and future electric power demand. For these electric utilities, demand-side options are especially important under today's conditions in which the capital cost of new generating capacity is increasing, international funds for expanding power sectors are not expected to be sufficient for meeting projected capacity needs, and environmental concerns over fossi! fuel emissions have raised new questions about constructing thermal power plants.

\section{S.2. OVERVIEW}

In the discussion, no attempt is made to extend or amplify the rich literature on the theoretical foundations of electricity pricing. Rather, using patterns of electricity consumption 
on power systems over time (i.e., load profiles) as the frame of reference, ${ }^{a}$ the paper explores evidence on the effectiveness of DSM--especially electricity pricing--in changing these patterns. The problew for most Western utilities is not necessarily just rapid increases in the absolute level of electricity demand (i.e., higher growth rates) but the irregularity of that demand on a daily, weekly, and seasonal basis. On any given day, periods of high demand of short duration ("peaks") typically require electric utilities to use less efficient generating sources to meet demand, resulting in higher short-run operating costs. Likewise, higher weather-related seasonal peaks ("system peaks") have led to higher capacity cosis to meet air conditioning and heating loads. Using an electric load curve as the frame of reference and depending on characteristics of individual power systems, utilities have pursued four DSM objectives in response to these consumption characteristics:

1. load shifting,

2. peak clipping,

3. valley filling, and

4. strategic conservation.

Numerous direct (e.g., direct load control of air conditioners) and indirect (e.g., electricity pricing) DSM programs have been implemented by both privately and publicly owned electric utilities in the United States to achieve these objectives, and the number is growing. Evidence of their effectiveness, however, is difficult to quantify because of the large number of privately (more than 200) and publicly (more than 2,000) owned electric utilities. One study (Keelin and Gellings, 1986) estimated that only 13 gigawatts (GW) of on-peak capacity out of more than $400 \mathrm{GW}$ in total peaking capacity was saved as the result of DSM programs in 1983. However, because of their increased usage, DSM programs are projected to be directly responsible for reducing peak demand by more than 10 percent in the year 2000 , and the percentage could be as high as 25 percent. The direct effects of DSM on system demand are equally difficult to quantify in Western Europe. In France, for example, the current daily load factor of 90 percent on the busiest day of the year is certainly due in large part to innovative electricity pricing and other DSM programs implemented as early as 1958, but it is difficult to distinguish their effects from secular trends such as changes in industrial composition, weather, lifestyle changes, and the like.

As a means to influence the pattern of electricity demand, the most widely adopted pricing strategy by Western utilities is time-of-use (TOU) pricing, which generally refers to electricity rates that vary over the course of a year: hour-by-hour, day-by-day, or season-byseason. Time-of-day (TOD) pricing (rates which vary over the course of a day), a specific form of the general class of TOU rates, has generally been effective in achieving the first load objective mentioned above for both low- and high voltage consumers: shifting electricity

\footnotetext{
"Note here the use of the terms consu mption and dernand as conventionally used in power system economics. Consumption (measured by $\mathrm{kWh}$ ) is the conventional way that "demand" is defined in economics: the amount of a product consumed over some specified period of time. "Demand" as used in the power industry, however, is the rate at which electricity is used, referring to the instantaneous use of generating capacity ( $\mathrm{kW}$ demand). An attempt is made to distinguish between the two throughout the remainder of the paper.

${ }^{b}$ Here we ignore electric utilities with excess capacity that have used DSM to promote increases in electricity consumption.
} 
consumption from peak to off-peak periods. ${ }^{c}$ And, at least for higher volume users (highvolume residential and higher-voltage commercial and industrial users), it has proven to be cost-effective in the United States. Western utilities have also used another form of a TOU tariff, an interruptible or curtailable (I/C) one, to reduce demand on days when capacity utilization is approaching its limit, usually offering rate incentives to large-volume, highvoltage consumers in return for shedding load for a limited amount of time on short notice. From every indication, these tariffs have been successful in reducing both U.S. and Western European capacity requirements.

Besides being used alone as a DSM option, TOD pricing has also been instrumental in implementing other DSM programs designed to achieve the first three objectives, particularly for low-voltage residential users. For load shifting and valley filling, the best examples come from Western Europe, where British and West German utilities have pioneered the use of TOD pricing to lure households to adopt thermal energy storage units for heating, shifting substantial amounts of winter peak kilowatt-hour (KWh) consumption to off-peak periods and dramatically improving residential load factors in the process. Western utilities have also used TOD pricing to promote direct load control programs aimed at reducing the absolute system peak. While many variants of these programs have been tried (consumer control through use of time clocks, thermostats and the like versus direct utility control through remote cycling) for different end uses (air conditioning, space heating, water heaters), the most successful in reducing peak load have proved to be direct load control of air conditioning systems by the utility, implemented by TOU tariffs.

The next two sections summarize the evidence for low- and high-voltage consumers, respectively, where low-voltage is defined exclusively as residential users and high-voltage encompasses all others: commercial, small industrial, and large industrial users. Section 5 relaxes the assumption of preannounced and fixed TOU tariffs that is implicit in the discussion in Sections 3 and 4, addressing experiments of Western utilities with exploiting advances in communication and metering technology to more closely match electricity rates with current operating costs. The final section addresses the relevance of the Western experience for developing countries.

\section{S.3. TOU RATES AND LOW-VOLTAGE USERS}

Based on results of U.S. residential TOD pricing experiments, TOD pricing is effective in inducing a shift in kilowatt-hour (KWh) electricity consumption from peak to offpeak zeriods. However, there was enough variability across experiments in both the types of utilities involved (e.g., warm-climate, summer-peaking vs. cold-climate, winter-peaking) and the types of experiments conducted and analyses performed (e.g., single vs. multiple-rate experiments, experimental designj to question the consistency of response to the experimental rate structures.

\footnotetext{
Note that a TOD tariff for a given utility typically includes all time periods mentioned in the text, incorporating rates which vary not onty between hours of the day, but also from weekdaye to weekends and from seasons of the year (winter and summer periods, for example).
} 
To address the consistency question, one study pooled data from five geographically diverse experiments--accounting for household characteristics, dwelling type, climate, and the penetration of electricity-using equipment--in estimating responses to TOD tariffs (Caves, Christensen, and Herriges, 1984). After controlling for the factors that influence electricity consumption, the evidence indicates a consistent response among low-voltage consumers. For an average consumer, the elasticity of substitution of off-peak for peak electricity is 0.13 , implying that 1.3 percent of peak-period consumption would be shifted to off-peak periods if the ratio of peak to off-peak prices were increased 10 percent. Characteristics of the tariff itself (peak-to-off-peak price ratio and length of the "peak period"), the amount of household electricity consumption, the types of electricity-using equipme:t, and the weather are important determinants of responsiveness to the rates.

These same factors that influence the degree of responsiveness, of course, are important in determining the tariff's cost-effectiveness. In making that determination (i.e., the discounted net benefits of adopting them), a reduction in a utility's short-run operating costs (e.g. fuel costs) associated with providing less on-peak power must be weighed along with (1) increased metering costs an' (2) increased consumer benefits from the tariff. The metering costs are an important consideration for low-voltage users because they represent a relatively large fraction of the total costs of serving individual customers.

Studies of the cost-effectiveness of the experimental U.S. tariffs generally showed that the higher the level of electricity consumption (at least $1,000 \mathrm{KWh}$ per month), the greater the likelihood that the tariff will prove cost-effective, or, at least, will be less cost-ineffective than for lower-consumption households. Also, the higher the ratio of peak to off-peak prices, the more likely the tariff will prove cost-effective. Finally, TOD tariffs for summer-peaking utilities with large air conditioning loads are more cost-effective than these same tariffs implemented by utilities in cooler climates without the same penetration of air-conditioners. Again, to the extent that consumers change their electricity-using stock of appliances in response to TOD rates in the longer term, the greater the likelihood that TOD tariffs will prove cost-effective for a larger class of customers.

Another factor that may determine whether or not TOD rates are cost-effective for a larger class of low-voltage consumers is participation: whether the tariff is voluntary or mandatory. There is some evidence to indicate that volunteers for residential TOD tariffs-even though they may consume the same percentage of electricity in peak periods under standard rates as an average household--respond to a greater degree than low-voltage users who are involuntarily placed on TOD tariffs, primarily because of educational and income levels and the types of electricity-using appliances they own. In fact, one study showed that the response of households under voluntary TOD rates is twice as large as the response would be if the same consumers were placed on a mandatory tariff.

Besides using pricing alone as a mechanism to shift $\mathrm{KWh}$-consumption from peak to off-peak periods for low-voltage users, TOU pricing has also been used in conjunction with other direct DSM programs, offering consumers an incentive to participate in these loadshifting programs. The best examples come from Western Europe, where British and West German utilities have pioneered the use of TOU pricing to induce adoption of thermal energy storage units for household heating, shifting substantial amounts of winter on-peak

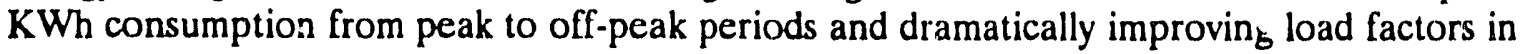


the process. In England and Wales, approximately one-half of electricity consumption is shifted from peak to off-peak periods for consumers adopting storage radiators, while increased penetration of storage heating devices in Germany contributed to increasing the peak-month load factor from 77 to 88 percent.

In addition to these low-voltage pricing-related DSM strategies designed to shift KWh-consumption from peak to off-peak periods, Western utilities have also used TOU pricing to promote direct load control programs aimed at reducing the absolute system peak (KW demand). While mary variants of these programs have been implemented (consumer control through use of time clocks, thermostats and the like versus direct utility control through radio, for example) for different electricity end uses (air conditioning, space heating, water heaters), the most successful seem to be direct ioad control of air conditioning systems by the utility, induced by favorable tariffs. In the United States, for example, it is estimated that air conditioner cycling programs lead to peak-day demand reductions on the order of 1.5 KW per customer.

\section{S.4. TOU RATES AND HIGH-VOLTAGE USERS}

Because metering costs are typically such a small fraction of the total cost cf supplying individual high-voltage electricity consumers, the question of cost-effectiveness for these consumers is generally not an issue, even with small changes in KWh-consumption betwee!. peak and off-peak periods. And, the evidence of that change is small, at least in the short run. In a study of ten U.S. utilities with mandatory TOU tariffs that included more than 6,000 high-voltage customers, for example, the estimated change in relative peak load upon introduction of TOD rates was less than one percent, with commercial customers more unresponsive $(0.29$ percent $)$ than higher-voltage users $(1.03$ percent $) .^{d}$

Even though the total response across industries is fairly small, responsiveness varies significantly by individual industry. Generally, energy-intensive, mechanical production processes producing $d$ iscrete loads lend themselves better to TOU pricing response than, say, industries with contin uus production processes. In studies of U.S. industries, wood products and cement productio/ ' generally show the largest short-run responses to TOU rates. In the longer run studies of both French and British industry, cement production exhibits the greatest response to TOU rates. In both countries, cement producers reduce load by as much as 50 percent during weekday peak periods and, on weekends when only off-peak tariffs apply, they retain an almost constant load at the level of highest off-peak, weekday consumption. The distinguishing characteristic of these industries is their ability to curtail operations during peak periods or switch production from peak to off-peak periods in response to the tariffs. Continuous process industries such as motor vehicle production i... petroleum refining, on the other hand, cannot curtail production and, therefore, exhibit very little response to TOU rates, unless individual plants have their own sources of power that can be used during peak periods.

\footnotetext{
${ }^{d}$ Relative peak $\mathrm{kWh}$ consumption in any given month is defined as the ratio of average $\mathrm{kWh}$ consumption during peak periods to average $\mathrm{kWh}$ consumption during all weekday hours. The change in relative peak $\mathrm{kWh}$ consumption is the difference between a current and prior year's monthly consumption.
} 
Besides using TOD pricing to shift high-voltage load, Western utilities have relied on a specific form of a TOU tariff, an interruptible or curtailable $(I / C)$ one, to reduce demand on days when capacity utilization is approaching its limit, offering rate reductions to largevolume customers in return for shedding load for a limited amount of time on short notice. ${ }^{\circ}$ From every indication, those tariffs have been successful in reducing both U.S. and Western European capacity requirements. In fact, based on a study of ten U.S. utilities with I/C rates, most of the customers under I/C tariffs reduced their load by an amount greater than what was agreed upon. In England and Wales where a form of an I/C tariff has been in existence for a number of years, more than 10 percent of total industrial load is shed by consumers volunteering for the tariff.

\section{S.5. FROM STATIC TO DYNAMIC TOU TARIFFS}

Historically, whether electricity tariffs ivere based on average or marginal costs in the ratemaking process of Western utilities, they 'were preset to reflect projected supply costs for different customer categories and, absent fuel adjustment clauses, lasted the length of a regulatory cycle: six months, one year, two years, depending on a utility's operating condition. Advances in communication (utility to customer to utility) and metering technology, however, have encouraged many utilities in the Inited States and Western Europe to experiment with real-time pricing (RTP), a dynamic furm of TOU pricing in which prices are transmitted to consumers on a more timely basis to more closely reflect actual operating costs, rather than just projections of those costs.

By more closely aligning prices with the actual costs of supplying electricity during different time periods, RTP will ideally allow the pricing mechanism to ration electricity at times of system peak, replacing many of the interventionist measures used by utilities at the moment. For example, rather than relying on TOD pricing to implement air conditioner cycling programs to shave residential loads or $\mathrm{I} / \mathrm{C}$ tariffs to totally interrupt or curtail industrial loads, RTP moves the ratemaking process toward market allocation of electricity by providing consumers the actual cost of electricity at times of system peak and allowing them to decide the quantity of electricity to purchase during these periods when costs and, therefore, prices are high. And, those peak prices can be significant. In an RTP experiment at Southern California Edison, for example, rates vary from as low as $\$ 0.018 / \mathrm{KWh}$ to as high as $\$ 1.36 / \mathrm{KWh}$ during peak periods on extremely hot summer weekdays.

Programs to date have varied. In one of the earliest experiments for residential customers in England, the British Broadcasting Company transmitted real-time electricity prices every five minutes; controlled appliances in English households were in turn shut off electronically when the prictexceeded a threshhold level. Under the French Peak Day Withdrawai (PDW) tariff implemented in 1982, the peak day is announced only one-half hour in advance, but it is limited to only 22 days of the year. In the PGE experiment, 15 commercial and industrial customers are provided price signals a day in advance on an hourly basis. At Southern California Edison, ten large commercial and industrial customers are provided three rate forecasts for planning purposes: (1) 90 days in advance, (2) on the

\footnotetext{
'An interruptible tariff implies that the customer must reduce consumption entirely, while a curtailable rate implies that the consumer must reduce consumption to some agreed upon level, not necessarily reducing it to zero.
} 
Monday of the upcoming week, and (3) a 24-hour ahead forecast, which is the actual rate structure in effect the next day.

The results of the experiments are mixed. In the more limited experiments such as the PDW tariff in France, more than 1,000 industrial customers took advantage of the voluntary tariff and it was extended to residential customers in 1985. By 1995, 2.5 million low-voltage users are expected to be on the tariff. The load reduction is substantial: $760 \mathrm{~mW}$ of industrial load are saved out of $1,300 \mathrm{~mW}$ of contracted load. With 60,000 residential consumers participating in $1988,200 \mathrm{~mW}$ of load were saved. In the more comprehensive experiments, the results are not so clear-cut. In the PGE experiment, the technology worked and participating customers saved on average 12 percent of their electricity costs in comparison with staying on PGE's standard TOD industrial tariff. In SCE's experiment, only two of ten corsumers responded to the tariff.

\section{S.6. RELEVANCE FOR DEVELOPING COUNTRIES}

Movenent to dynamic electricity tariffs represents a formidable technical challenge for Western utilities in adopting technology to bring electricity tariffs closer in line with actual operating costs on anything much more than an experimental scale. Providing hourly prices in "real time" with new communication and metering technologies for larger groups of customers across all hours of the year is evolutionary, and not a costless undertaking. Indeed, for many U.S. utilities in particular, which historically have used embedded (average) costs in ratemaking, dynamic pricing represents a quantum leap in conveying prices to consumers.

For many developing countries, confronting the RTP challenge is a longer-term undertaking, certainly not a first $\mathrm{m}$, second-, or even third-order priority at this point. In fact, with respect to ratemaking, the most urgent priority for many countries is not adopting new technologies, but developing both the political will and a social mechanism for rationalizing electricity tariffs: raising them to cost-based levels. As the Western world discovered in the aftermath of the energy shocks of the 1970s, most energy efficiency gains are attributable to higher energy costs. For the power sectors in many developing countries, this first order priority of rationalizing electricity prices can perform this same conservation-inducing function: slowing load growth, reducing capacity requirenents, and decreasing the need for capital and operating subsidies from national governments and reducing foreign debt exposure in the process.

The legacy of the Western experience with TOU electricity pricing for developing countries is that movement to cost-based pricing should include temporal considerations: the benefits to both consumers and electric utilities can generally be improved by not just simply basing electricity prices on average costs incurred during the year, but by more closely reflecting changes in costs over time (day-by-day, season-by-season) in those tariffs. As with any DSM strategy, however, the benefits accruing to any form of TOU pricing are utilityspecific, depending on such interreiated characteristics as development status, industrial composition, sectoral electricity consumption, income levels, and the like. The Western experience, then, provides a frame of reference, some guidelines for what is possible, not a precise model to transfer for application in all countries. 
Drawing upon the Western experience, using residential TOD pricing alone as a DSM strategy cannot generally be prescribed as a cost-effective means to induce load-shifting from peak to rif-peak periods in developing countries. First of all, the embryonic stage of residential loads in many developing countries, relying on relatively unsophisticated electricityusing equipment with low levels of per-capita electricity consumption, is a major limiting factor. Also, the additional metering problems and costs associated with TOD pricing woulc exacerbate an already troublesome problem for many countries. However, for middle-income developing countries experiencing both changing and rapid load growth due to the penetration of residential air conditioners, for exampis, TOD pricing may prove to be an economically attractive option. Of special interest here may be the direct air-conditioning load control programs implemented in the West. Extending from residential to commercial loads (hotels, office buildings), this may prove to be an economically attractive option with wider applicability than just middle-income countries.

Of more general applicability to the developing world is the Western experience with industrial TOU rates. Even though the available evidence suggests meager load shifting from peak to off-peak periods for U.S. industrial consumers as a whole upon introduction of TOD rates--on the order of one percent--the composition of the manufacturing sector in Western economies is not typical of most of the developing world. What is most relevant from the Western experience is that the response is highly variable by industry. For many developing economies, cement production, for example, is a large and important industry for intrastructural development, and cement production generally shows the largest short-and long-run responses to TOD rates in Western economies. Also, in many countries where power availability and reliability concerns have forced many manufacturers to develop their own power sources, the Western experience shows that these manufacturers are most amenable to TOD rates. Finally, interruptible and curtailable tariffs should have wide applicability in developing economies. They have generally proved effective in red icing highvoltage load on system peak days for Western utilities, thereby eliminating capacity requirements. 


\section{INTRODUCIION TO DEMAND-SIDE MANAGEMENT (DSM)}

\subsection{OVERVIEW}

In the United States, interest in using demand-side measures to shape load is a fairly recent phenomenon. Prior to the early 1970 s, electric utilities generally minimized power supply costs, given the corsumption patterns of consumers. However, since that time the operating environment of electric utilities has changed dramatically. Prompted in large measure hy (1) increased penetration of electric air conditioning and space heating in the residential sector, along with (2) higher supply (both fuel and capacity) costs and (3) increasing environmental concerns about new power plant construction, electric utilities have increasirgly lnoked to the demand side as a source of resources for meeting load commitments. Electric utilities in Western Europe, on the other hand, implemented demandshaping measures on a large scale much earlier than U.S. utilities. Electricite de France, for example, th. French power monopoly and an innovator in using demand-side measures to influence electricity demand, implemented DSM measures as early as 1958 in response to shortages of hydroelectric capacity in winter months, which strained its ability to service winter heating loads. Even countries with predominantly hydroelectric power gerieration systems, such as Norway, have introduced some form of demand control.

All of these activities pursued by electric utilities in the Western world fall under the umbrella of demand-side management (DSM), which in its most general form refers to any activity that a utility undertakes to influence its cusiomers' use of electricity. The TOU pricing schemes implemented in Western Europe and, more recently by U.S. utilities, are an indirect DSM activity, using prices as an incentive for consumers to switch consumption from times of peak demand to off-peak periods. By offering a rate structure based on supply cost, a utility can influence consumers to make electricity consumption decisions that are in the common interest of the consumer and the utility. ${ }^{1}$ Electric utilities can also take more direct measures to influence demand. The alternatives range from relatively simple measures such as facilitating more efficient electricity use through energy audits to directly controlling the flow of current to electricity-using equipment. Indeed, one of the more promising methods of shaving peak load in Western utilities has involved very active participation by the utilities themselves: remote (utility-controlled) cycling of air conditioners so that energy is not used at peak periods. Another prominent direct measure is promoting thermal storage of electricity for use at other than peak time periods. Utilities in Great Britain have long had a thermal storage program for low-voltage customers, selling thermal radiators out of utilityowned stores to promote off-peak (night-time) use of electricity.

Many of these direct methods of shaping an electric utility's load curve, however, oftentimes require a financial incentive for customers to adopt therit. Financial incentives can take several forms. The international oil price shocks of the 1970 s prompted governments to promote energy conservation and alternative energy sources (such as solar energy) by providing tax incentives. Utilities themselves offered conservation retrofit programs to their

\footnotetext{
${ }^{1}$ Besides pricing, there are other indirect approaches to influence electricity-consuming decisions: for example, actvertising or consumer awareness programs that seek to educate consumers on such issues as energy conservation are widety used.
} 
customers at zero or less than market rates of interest. As will be discussed in detail below, the pricing mecnanism has been used extensively as a financial inducement to implement other demand-side measures. Direct load control programs, for example, are usually promoted in conjun tion with a time-of-day rate structure in which it is in the cusiomer's interest to consume power Juring offpeak periods.

Numerous permanent and experimental DSM programs have been implemented by both privately and publicly owned electric utilities in the United States, ${ }^{2}$ and the number is growing. Although up-to-date and comprehensive information is lacking, one study (Keelin and Gellings, 1986) estimated that more than 40 million electricity customers were participating in DSM programs in 1983, up from less than 20 million in 1977. The net load effects of these programs are also difficult to quantify, not only because of the large number of U.S. electric vtilities, but also because of a wide range of objectives in undertaking DSM programs. Keelin and Gellings suggest that the net impact of DSM programs has been fairly small, at least through 1983. Defining electric energy savings as the difference between the historical trend of electricity growth and actual electricity demand in 1983, the authors estimated a total electricity capacity savings of 241 gigawatts (GW) in 1983 . Of this, the net impact of DSM programs was only $13 \mathrm{GW}$. The remainder of the savings was due to price $(128 \mathrm{GW})$ and income (100 GW) effects. How'ever, since 1983 utilities have pursued demand-side planning more vigorously as a result of in reasing regulatory pressure and the fact that it is oftentimes in their economic interest io do so. In fact, a more recent study (Faruqui, Seiden, and Braithwait, 1990) estimated that forecasted (expected) savings of slectricity demand attributable to demand-reducing DSM programs, however, is more encouraging. In the year 2000, for example, onpeak electricity demand is projected to be 682 GW, if no DSM programs were implemented. The forecasted net effect of DSM programs is to reduce demand by $45 \mathrm{GW}$ (6.5 percent) to $63^{*}$, GW of onpeak demand.

The types of programs vary, depending on the load objectives of individual utilities, which include six all-encompassing, but not mutually exclusive, goals:

1. peak clipping: reducing peak commitments to lower capacity requirements and/or to reduce the use of costly fuels during peak hours;

2. valley filling: promoting electricity consumption during offpeak hours to improve system load factor;

3. load shifting: inducing switches from peak to offpeak periods;

4. strategic conservation: promoting an across-the-board reduction in electricity consumption through improving the efficiency of electricity-using equipment;

5. strategic load growth: promoting electricity consumption for capacity-rich utilities; and

6. flexible load shape: promoting service reliability.

\footnotetext{
${ }^{2}$ Using broad ownership types, electric utilities in the United States can be categorized as (1) investor-owned utilities (IOUs), (2) municipally ownerl systems, state and county power projects, and joint action agencies, (3) rural electric cooperatives, and (4) federal power proiects. IOUs account for approximately three-quarters of the indusiry on a sales and investment basis.
} 
Given a load objective, selection of a specific DSM program (or programs) is utilityspecific, of ' Jurse, depending or. both characteristics of the power system and the nature of demand. $^{3}$ Concentrating on demand-side alternatives, the first three objectives are emphasized in this study: peak clipping, valley filling, and load shifting.

The fourth obiective, strategic conservation, usually refers to improving the technical sfficiency of eicctricity-using equipment. In the United States, for exumple, lighting programs have been widely used because of lighting's large share of the total load of U.S. electric utilities, accounting for 20-25 percent of total electricity sales and 25-40 percent of daytime peak load. In a recent survey of U.S. electric utilities, Isaksen (1987) found that 60 percent of the respondents had implemented some type of lighting program to accoinplish DSM goass. Of the utilities engaged in efficient lighting programs, 92 percent were involved with encouraging commercial and industrial customers to use new lighting technologies and improved system design.

While not specifically addressed here, the role of electricity pricing for conservation purposes cannot be overstated. As other studies have pointed out (Hill, 1987, for example), the inability of many countries to raise energy prices (particularly electricity) to cost-based levels is perhaps the most pervasive energy-related problem in developing countries. The political unwillingness of many of these countries to use the pricing mechanism as a conservation-inducing device has not only led to gross inefficiency in energy sectors, but has significantly contributed to other macroeconomic problems as well: e.g., a drain on foreign exchange and increased foreign debt exposure.

\section{A CLOSER LOOK AT ELECTRICITY PRICING}

Besides TOU pricing, U.S. electric utilities have implemeitted a wide range of both experimental and permanent rate structures. Evidence of that diversity is provided in Table 1 , presenting the results of two surveys on the types of electricity rate structures in existence for investor-owned electric utilities in 1983 and 1986. Note the definitions. Where this study definis TOU rates generically, including rates which vary by time over any period of the year (hour-to-hour, day-to-day, season-to-season, and during times of system peak), the surveys are much more restrictive in their definition: what is here referred to strictly as time-of-day rates, varyin $_{b}$ b.uur-by-hour. Thus, 'he survey categorizes interruptible/curtailable rates separately.

The survey results show a significant increase in the implementation of the various rate structures over the three-year period. On a percentage basis, two of the largest increrises were in industrial incentive and partial requirement rates. The former is particularly important for those service areas which are economically declining and/or face competition

\footnotetext{
${ }^{3}$ Here, we are restricting the discussion exclusively to demand-side options. It may be the case, however, that a utility may have supply-side options available to it also. This means that DSM options must be evaluated in conjunction with the supply-side alternatives also. For example, it may be the case that a given utility's need for additional capacity because of high load growth could be more economically accommodated by improving the efficiency of supply (power plant rehabilitation, improvement in T\&D losses) rather than engaging in $\Gamma \Delta M$ activities. This is especially tru: in many developing countries suffering from suboptimal conversion efficie ucies in power generation and/or excessive transmission and distribution losses. What is required in these cases is a systematic assessment of all options at the disposal of a utility, given its load objectives.
} 
from competing fuels, such as natural gas. The large increase in partial requirement rates suggest an increase either in the absolute number of cogenerators or the number who find tariffs trom the central grid more economically attractive than the cost of nroducing their own power.

Table 1

Implemented Electricity Tariffs in the United States

U.S. Investor-Owned Utilities Survey Results"

1983 and 1986

Type of Rate

1983

1986

\begin{tabular}{lcccc} 
& Number & $\%$ & Number & $\%$ \\
\hline Time-of-Use & 85 & 69 & 92 & 84 \\
Interruptible/Curtailable & 69 & 56 & 78 & 71 \\
Industrial Incentive/Economic Development & 11 & 9 & 28 & 25 \\
Inverted Block & 21 & 17 & 20 & 18 \\
Special Purpose Incentive & 29 & 24 & 42 & 38 \\
Residential Demand & 11 & 9 & 10 & 9 \\
Vintage & 2 & 2 & 0 & 0 \\
Demand Subscription & 2 & 2 & 2 & 2 \\
Partial Requirement & 26 & 21 & 43 & 39 \\
Coincident Use & 1 & 1 & 1 & 1 \\
Low-Income Residential & 9 & 7 & 15 & 14 \\
Other & 12 & 10 & 13 & 12 \\
\hline
\end{tabular}

SOURCE: Ebasco Business Consulting Company $(1985,1988)$.

"For 1986, 156 investor-owned utilities were surveyed; 110 (more than 70 percent) responded. The corresponding numbers for 1983 were 157 and 123 (more than 75 perant).

bor purposes of the survey, the rates were defined as follows:

Time-of-Use: a rate varying by usage during the day; Intermuptible/Curtailable: a rate giving credit to reduce usage to some prearranged level upon notification from the utility; Industrial Incentive/Economic Development: a rate keeping industrial customers on the grid or attracting new custorners; Inverted Block: a rate in which the demand or energy charge increases with usage; Special Purpose Incentive: a rate providing a credit for participating in a utility program (e.g., air-conditioner cycling, conservation); Residential Demand: a rate having a demand component (S/KW), excluding TOU rates; Vintage: a rate in which historic consumption is priced differently than new consumption; Demand Subscription: a rate in which a customer receives a rebate for subscribing to a maximum level of demand which never can be exceeded because electric service is shut off; Partial Requirement: a rate, different from the standard one, applying to consumers who purchase only a portion of their power needs from the utility (e.g., cogenerators); Coincident Use: a rate in which a demand charge ( $\$ / \mathbf{K W})$ goes into effect at the time of system peak; and Low-Income Residential: a rate providing a discount to low-income consumers. 
Excluding partial requirement tariffs, the three tariffs with the greatest penetration are the ones under investigation in this study: time-of-use, interruptible, and special purpose tariffs. Time-of-use tariffs are the most widely used of any of the tariffs in existence in the United States, with 84 percent of the utilities reporting implementation for at least one customer class in 1986. Many of the 110 utilities responding to the survey had TOU rates implemented for two or more sectors, with 73 and 79 of the utilities, respectively, having TOU rates in the commercial and industrial sectors. In a ddition to the utilities reporting rate types implemented in Table 1, a number of utilities had formulated and/or proposed a TOU rate structure, including 17 in the commercial and 19 in the industrial sectors.

Interruptible tariffs, a more general form of TOU rates, are the second most pervasive tariff used by U.S. utilities with nearly three-quarters of the utilities responding that they had some form of the tariff implemented in 1986 (Table 1 ) and 28 different $I^{\prime}$ C tariffs in various proposal stages. While the majority of implemented $\mathrm{I} / \mathrm{C}$ tariffs were for larger-voltage customers (commercial and industrial), five programs existed for residential and eight for agricultural. On the other hand, the majority of special purpase incentive tariffs were in the residential and commercial sectors (36 and 23 programs, respectively), with highest-voltage customers only having 13 programs.

In Western Europe, France has been the leader in implementing innovative electricity pricing programs. Electricite de France developed marginal cost price schedules for highvoltage users as early as 1955 and implemented a voluntary industrial TOU rate for highvoltage users in 1958. A decade later, the tariff was made mandatory. In the residential sector, a voluntary TOU pricing program has encouraged the use of storage water heaters. Besides the French experience, TOU pricing has been used on hydro- and thermal-dominant power systems in Western Europe. Norway, for example, a hydro-based system in which there is a greater tendency for seasonal rather diurnal changes in operating costs, implemented a seasonal tariff for high-voltage users to reflect the seasonality of water supply: in the summer months when water is more plentiful, the energy charge has historically been one-half of that in winter. Similarly, besides a varying seasonal energy charge, one of the two demand charges of the Swedish State Power Board's high-voltage tariff is a type of TOU tariff, based on average rate of demand over any 6-hour period. At the other extreme, the thermal-dominant British system has long had optional high-voltage TOU tariffs in effect and, along with West Germany, has pioneered the use of thermal storage heating systems for residential customers, using a TOU tariff as a financial incentive to participate.

\subsection{REMAINDER OF REPORT}

The focus in this study is on empirical aspects of these pricing-related DSM strategies, rather than their theoretical foundation. That foundation has been enriched significantly since the seminal contributions of Boiteux (1949) and Steiner (1957), including the more recent treatment of dynamic TOU pricing by Schweppe, Caramanis, Tabors and Bohn (1988). Before proceeding to a detailed discussion of these TOU pricing initiatives for low-and highvoltage electricity users in Sections 3 and 4, respectively, the next section discusses the problems involved in measuring customer response to TOU rates.

Unfortunately, a one-to-one correspondence between the DSM experience of one utility and another does not exist. The economic attractiveness and, therefore, the selection

\footnotetext{
4Similar to the U.S. experience with electricity rate structures, it is not possible to provide a comprehensive overview of all of the different types of electricity tariffs that have been implemented in Western Europe. The interested reader is referred to de Voghel (1989) for a recent review of tariffs in existence.
} 
and implementation of any DSM option is necessarily utility-specific, depending on the operating characteristics of individual utilities (such as load growth, generating mix, load factor, and the penetration of electricity-using appliances by its consumers), which determine the load objectives of individual utilities. Oftentimes, economic theory does not even provide proper guidelines. While matching prices with the costs of producing electricity (time-of-use pricing) is well-established as an economic efficiency objective, for example, it may well be that doing this for some classes of customers (low-voltage customers, for example) may not prove to be cost-effective for an individual utility when additional metering and administrative costs are taken into consideration. Section 5 reviews the issues involved in evaluating net benefits, emphasizing empirical studies of actual programs in calculating net benefits.

Finally, improvements in metering technology have now advanced to the point where electric utilities have the capability to experiment with more dynamic pricing structures; that is, pricing structures that more closely match electricity rates with actual system operating costs, rather than expected or forecasted costs by time of day. Advances in communication systems and electronic metering devices make it possible to transmit prices to consumers in "real time," based on current operating conditions, minutes or hours before the prices take effect. Section 6 reviews the U.S. experience with these pricing systems, concentrating on the ongoing experiments at three U.S. utilities. 


\section{RESPONSE TO TOU RATES: THE MEASUREMENT PROBLEM}

Figure 1 illustrates a hypothetical utility's average daily load curve prior to and after implementing TOD pricing, assuming a six-hour peak period from noon until 6:00 p.m. All other times of the day are off-peak periods. ${ }^{s}$ The point $\mathrm{P}$ represents maximum $\mathrm{KW}$ demand under the conventional tariff, while $Q$ is the corresponding level under the TOD tariff. The areas $A$ plus $B$ represent $K W h$ consuinption prior to implementing TOD rates, while the sum of areas $B, C$, and $D$ is the amount of consumption after TOD rates have been implemented. Thus, area $\mathrm{A}$ is the amount of lost $\mathrm{KWh}$ consumption during the peak period as a result of TOD pricing, while $C$ plus $D$ is the amount of increased off-peak consumption.

Figure 1

Hypothetical Load Curve

Before and After Introduction of TOD Rates

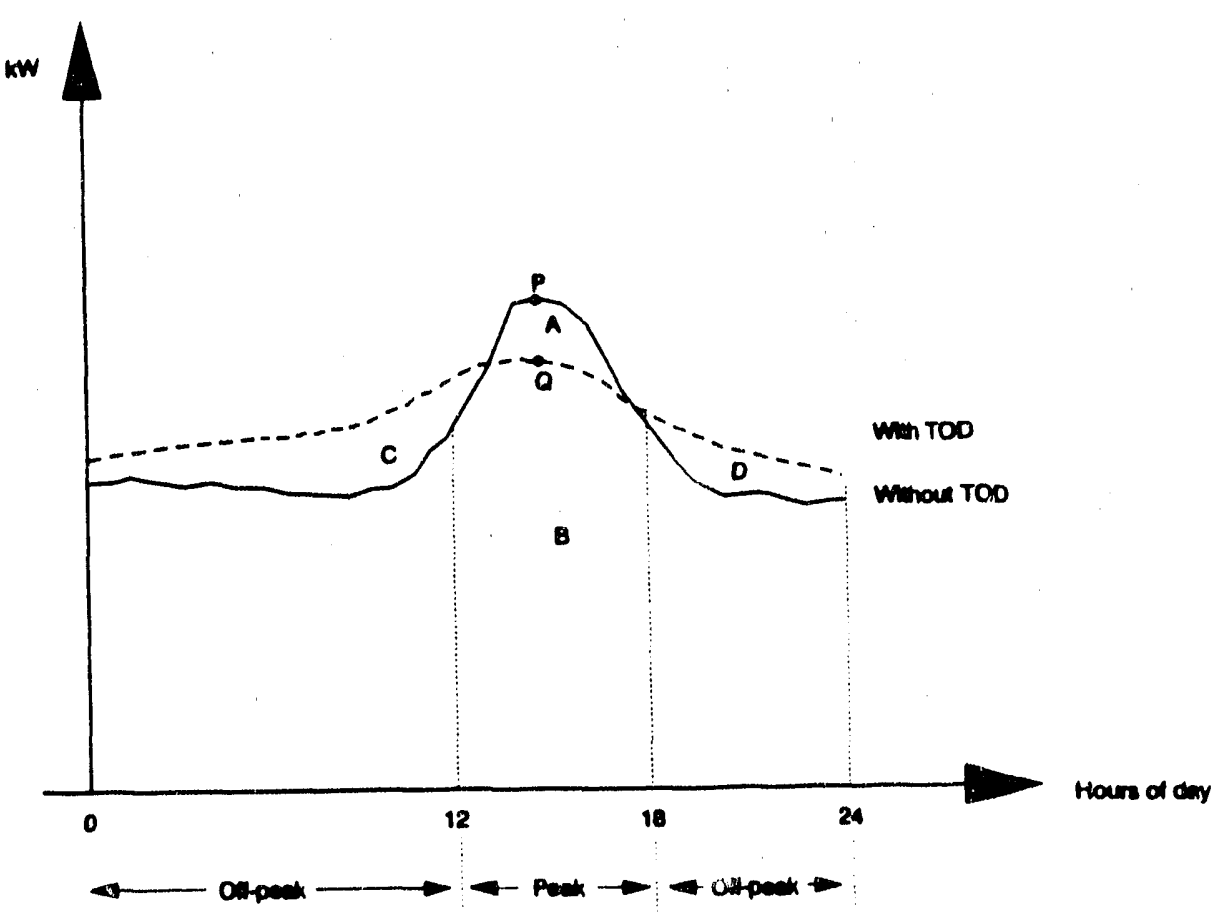

${ }^{5}$ Mamy TOD tariffs include different rates for three periods: peak, intermediate (or shoulder), and off-peak. To sim lify the presencation, we include only two periods. The discussion, however, can be generalized to as many periods as one chooses. 
An ideal study of consumer response to TOD rates would measure changes in both KWh consumption (C plus D versus $A$ in Figure 1 ) and $\mathrm{KW}$ demand (reduction from point $\mathrm{P}$ to Q). The reduction in KWh-consumption at times of daily system peak is important because operating costs are generally higher during these periods due to the use of peaking units (in the absence of purchased power sources) and, if the load curve in Figure 1 represented the day of the absolute peak on a utility's power cielivery system, the amount of $\mathrm{KW}$ reduction ( $\mathrm{P}$ less $\mathrm{Q}$ ) determines the reduction in capacity needs. Unfortunately, data limitations in many cases preclude precise measurement of the $\mathrm{KWh}$ and $\mathrm{KW}$ response to TOD rates.

Own-price and cross price elasticities of demand for both peak and off-peak periods are important summary measures of $\mathrm{KWh}$ response to TOD rates, quantifying the rate of change in consumption during these periods in response to changes in peak to off-peak price ratios and other factors that influence electricity consumption (e.g., household size and income, weather, types of electricity-consuming durables). These price elasticity estimates can be used in (1) cost-benefit studies and, in a related way, (2) simulations of the tariff's effects on the operating performance of the utility (e.g., profit, cash flow). ${ }^{6}$ Also, one would ideally want to obtain long run estimates of these response measures: changes in consumption after a period of time sufficient in length for consumers to adjust their stock of electricity-using equipment in response to the TOD tariff.

At first glance, the experience of Western European utilities with residential TOD tariffs would seem the most attractive as a source of long-term response estimates because some of the tariffs in those countries were implemented as far back as the early 1960 s. Unfortunately, TOD pricing in Western Europe was not implemented as an experiment: data on consumption prior to the introduction of TOD rates (i.e., control data) were not collected for use with post-TOD consumption data to estimate measures of customers' response. Therefore, evidence on the effect of TOD tariffs on customer response for Western European utilities is generally limited to load curve analysis: inferring from the rate structure and the post-TOD load curve the magnitude and pattern of response, with no ability to statistically control for the impacts of other factors that may have influenced load changes. Changes in some of these load curves will be used in Section 5 to show the effect of TOU pricing in implementing other demand-side programs.

The experience with TOD pricing in the United States, on the other hand, is a bit different. Prompted by the first oil price shock in the 1970s, a number of residential TOD pricing experiments were conducted, providing sufficient data in many cases for analysts to calculate relevant price elasticities. Unfortunately, these estimates measure short-run responses because the experiments were not conducted over a period of time sufficient in length for consumers to make adjustments to their electricity-using stock of durables. The elasticity estimates from these experiments discussed in the next section will be used as

\footnotetext{
${ }^{6}$ The elasticity of substitution between peak and off-peak $\mathrm{kWh}$ consumption is an alternative measure of t'ie tariff's effect that can be derived from price elasticity estimates.

${ }^{7}$ Where there is seasonal variation in TOD prices, however, and where one of the seasons does not have a peak-period component to it, it is passible to estimate elasticities using data for both of the seasons. Acton and McKay (1984) used this approach with French and British seasonal data.
} 
evidence of low-voltage consumer response to TOD rates. It may be safe to conclude, then, that the estimated responses are a conservative estimate of those which would be obtained as measures of longer term responses.

Data limitations are also impediments to measuring changes in peak KW demand in response ' $J$ TOD rates, both on an average weekday and on days of absolute system peak. To illustrate the problem, Figure 2 presents a hypothetical characterization of a utility's

Figure 2

Hypothetical Load Curve

Different System Peaks

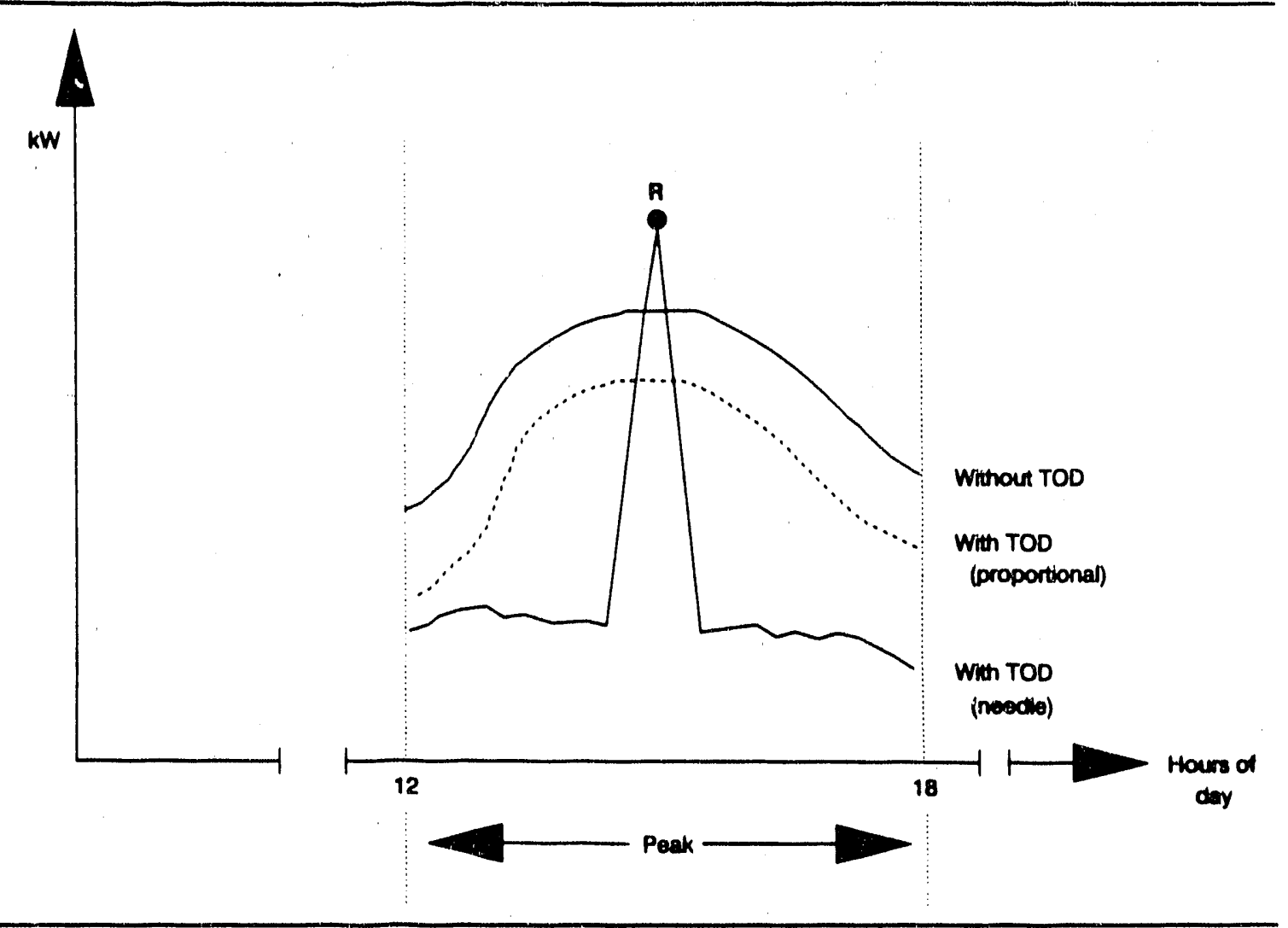

peak-period load on an average weekday before introducing a TOD tariff and after its introduction under two scenarios: (1) proportional to the load prior to implementing TOD rates and (2) a somewhit exaggerated "needle" peak. In the absence of data on KW demand during peak periods (i.e., data only on KWh consumption prior to and after implementing TOD rates), consumer response studies implicitly assume that the shape of the load curve after introducing TOD rates is proportional to the pre-TOD curve. It is possible, however, to experience a significant reduction in total $\mathrm{KWh}$ consumption during peak periods without a corresponding reduction in absolute peak demand, or even a case in which peak demand 
increases as the example of the "needle peak" in Figure 2 illustrates. $\mathrm{H}$ re, $\mathrm{KW}$ demand is maintained at a high level for a very short period of time, say less than 30 minutes, even though peak-period KWh consumption declines in response to TOD rates. Although the "needle peak" problem has obvious ramifications for capacity requirements on a power delivery system, the fine level of detail required for including it in empirical studies of consumer response makes it difficult to capture. This problem should be kept in mind in the consumer response discussion which follows.

Where the absolute peak problem is directly addressed, however, is in studies of consumer response to $\mathrm{I} / \mathrm{C}$ tariffs. A complicating problem here is knowledge of what $\mathrm{KW}$ demand would have been in the absence of the tariff for comparison with actual demand during an interruption to measure load relief. Interpreting the load curve in Figure 2 as that for one industrial customer and assuming that point $\mathrm{R}$ is the level of $\mathrm{kW}$ demand in the absence of an interruption under an $\mathrm{I} / \mathrm{C}$ tariff, the problem is determining what level of demand the point $\mathrm{R}$ represents if electricity usage during that period of the day were not interrupted. Various techniques have been employed to make that determination; in a study of ten utilities under I/C tariffs discussed in Section 4, regression analysis was used employing a model developed with data for all non-interruption days to project what consumption would have been in the absence of an interruption. 


\section{RESPONSE TO TOU TARIFFS: LOW-VOLTAGE USERS}

The most widely adopted pricing strategy by Western utilities to manage this type of low-voltage load is diurnally varying rates--time-of-day (TOD) pricing--which is a specific form of the more general class of time-of-use (TOU) rates which vary over the course of a year: hour-by-hour, day-by-day, or season-by-season. ${ }^{8}$ TOD rates are the oretically appealing: consumers who cause daily peaks should bear the burden of paying for the relatively higher running costs resulting from using peaking units during those periods. Likewise, consumers contributing to seasonal peaks--such as using air-conditioners--should bear the cost of building the capacity needed to meet the peaks.

Table 2 quantifies the pervasiveness of residential TOD rates for U.S. electric utilities, providing the results of two surveys on implemented electricity rate structures in the residential sector in 1983 and 1986. In 1986, 61 percent of the utilities had implemented time-of-use rates, up from 51 percent in $1983 .^{9}$ Another important type of TOU tariff is an incentive-based rate (from Table 2, a third of U.S. utilities had implemented them in 1986, up from a fifth in 1983), which typicaily has a time-varying element to encourage consumers to participate in a utility-sponsored program. Rates used to encourage various cycling programs (e.g., air conditioners, hot water heaters) and thermal energy storage systems are the most prominent incentive-based rate among Western utilities. Although interruptible/curtailable tariffs are not as widespread for low-voltage consumers because of individual consumer load size (only five percent of the utilities had adopted them in 1986), they are another type of TOU tariff widely used for higher-volume, industrial users.

\subsection{INDITIDUAL TOD EXPERIMENTS}

Employing their usefulness in providing insights for other utilities on customer response to TOD rates as the sole criterion for evaluation, the residential TOD pricing experiements viewed individually are generally considered to be lacking. There were serious design problems with many of the experiments. Several experiments considered only one TOD rate, which makes it difficult to draw inferences about any other rate designs. Some of the experiments suffered from other design failures. ${ }^{10}$

\footnotetext{
${ }^{8}$ Note that a $T O D$ tariff for a given utility typically includes all time periods mentioned in the text, incorporating rates that vary not only between hours of the day, but also from weekdays to weekends and from seasons of the year (winter and summer periods, for example).

${ }^{9}$ For purposes of the surveys, TOU rates were defined narrowly to include only rates that vary over the course of a day; in this paper, these are defined as time-of-day (TOD) rates.

${ }^{10}$ Ten experiments were initiated in 1975, including ones in Arizona, Arkansas, Connerticut, California (Los Angeles), New Jersey, Ohio, Wisconsin, Vermont, Michigan, and New York. In 1976, six more were added in California, North Carolina, Oklahoma, Puerto Rico, Rhode Island, and Washingtnn. For overviews of the DOE experiments, see Aigner (1985), Miedema, Lee, and White (1981), Faruqui and Malko (1983), and Acton (1982).
} 
Table 2

Implemented Electricity Tariffs in the $U_{\text {. }}$ S. Residential Sector

Survey Results"

1983 and 1986

\begin{tabular}{|c|c|c|c|c|}
\hline \multirow{2}{*}{ Type of Rate } & \multicolumn{2}{|c|}{1983} & \multicolumn{2}{|c|}{1986} \\
\hline & Number & $\%$ & Number & $\%$ \\
\hline Time-of-Use & 63 & 51 & 67 & 61 \\
\hline Inte :ruptible/Curtailable & 3 & 2 & 5 & 5 \\
\hline Inverted Block & 20 & 16 & 18 & 16 \\
\hline Special Purpose Incentive & 25 & 20 & 36 & 33 \\
\hline Residential Demand & 11 & 9 & 10 & 9 \\
\hline Demand Subscription & 2 & 2 & 1 & 1 \\
\hline Partial Requirement & 6 & 5 & 13 & 12 \\
\hline Low-Income Residential & 9 & 7 & 15 & 14 \\
\hline Other & 8 & 7 & 9 & 8 \\
\hline
\end{tabular}

SOURCE: Ebasco Business Consulting Company $(1985,1988)$.

"For the 1986 survey, 156 investor-owned utilities were surveyed; 110 (more than 70 percent) responded. The corresponding numbers for 1983 were 157 and 123 (more than 75 percent).

'For purposes of the survey, the rates were defined as follows:

Time-of-Use: a rate varying by usage during the day; Interruptible/Curtailable: a rate giving credit to reduce usage to some prearrainged level upon notilication from the utility; Inverted Block: a rate in which the demand or energy charge increases with usage; Special Purpose Incentive: a rate providing a credit for participating in a utility progl:am (c.g., air-conditioner cycling, conservation); Residential Demand: a rate having a demand component (\$, KW), excluding TOU rates; Demand Subscription: a rate in which a customer receives a rebate for subscribing 1:0 a maximum level of demand which never can be exceeded because electric service is shut off; Partial Requiremient: a rate, different from the standard one, applying to consumers who purchase only a portion of their power needs from the utility (e.g., cogenerators); and Low-Income Residential: a rate providing a discount to low.jnciome consumers.

However, Caves, Christensen, and Herriges (1984) pooled data from five of the experiments (listed as individual experiments in Table 3) to determine if there was a consistent response to residential TOD rates, given differences in customer characteristics such as household size, income, electricity-using appliances, and weather. If customer response were found to be consistent--given those factors that influence electricity consumption--other electric utilities could use the results to estimate responsiveness in their individual service territories by including the appropriate demographics in the model. The estimated customer response (i.e., price elasticity of demand) could then be used in costbenefit analyses of residential TOD rates. Caves et al. concluded that there was a consistent 
response across the five utilities. ${ }^{11}$ Before proceeding to a discussion of their study, however, it may be instructive to look at the five individual experiments described in Table 3 in greater detail.

Table 3

Summary of Five U.S. Residential TOD Pricing Experiments

\begin{tabular}{|c|c|c|c|c|c|}
\hline & CLP" & LADWP $^{b}$ & $\mathrm{SCE}^{\mathrm{c}}$ & $\mathrm{CPL}^{\mathrm{d}}$ & WPSe \\
\hline \multicolumn{6}{|l|}{ Experimental Design: } \\
\hline $\begin{array}{l}\text { Number of Rates } \\
\text { Peak:Offpeak Prices } \\
\text { Peak Length (Hours) } \\
\text { Test Duration (Years) }\end{array}$ & $\begin{array}{c}1 \\
16 \\
4 \\
1\end{array}$ & $\begin{array}{c}40 \\
2.5-9.0 \\
3-12 \\
2.5\end{array}$ & $\begin{array}{c}4 \\
3.0-9.0 \\
10 \\
2\end{array}$ & $\begin{array}{c}13 \\
1.2-6.2 \\
8-12 \\
1.5\end{array}$ & $\begin{array}{c}20 \\
2.0-8.0 \\
6-12 \\
3\end{array}$ \\
\hline \multicolumn{6}{|l|}{ Results: } \\
\hline $\begin{array}{c}\text { Peak Elasticity-Low } \\
\text {-High }\end{array}$ & $\begin{array}{l}-0.18 \\
-0.35\end{array}$ & $\begin{array}{l}-0.00 \\
-0.42\end{array}$ & $\begin{array}{l}-0.58^{\prime} \\
-0.68^{\prime}\end{array}$ & $\begin{array}{l}-0.00 \\
-0.23\end{array}$ & $\begin{array}{l}-0.22 \\
-0.61\end{array}$ \\
\hline $\begin{array}{c}\text { Offpeak Elasticity-Low } \\
\text {-High }\end{array}$ & $\begin{array}{l}-0.18 \\
-0.29\end{array}$ & $\begin{array}{l}-0.01 \\
-0.31\end{array}$ & $\begin{array}{l}-0.31^{\prime} \\
-0.49^{\prime}\end{array}$ & * & $\begin{array}{l}-0.20 \\
-0.45\end{array}$ \\
\hline $\begin{array}{l}\text { Peak Reduction (KWh \%) } \\
\text { System Peak Reduction (MW \%) }\end{array}$ & $19-31$ & $\begin{array}{l}\text { NA } \\
\text { NA }\end{array}$ & $\begin{array}{c}16 \cdot 26 \\
\text { NA }\end{array}$ & $\begin{array}{c}0-16 \\
30-40\end{array}$ & $\begin{array}{l}21-26 \\
32-40\end{array}$ \\
\hline
\end{tabular}

SOURCES: Miedema, Lee, and White (1981), White, Clayton, Alexander, and Duncan (1979), Miedema, White, Clayton, Alexander, and Kumm (1981), Lee, Clayton, and Boutilier (1981), Lee, Miedema, Lifson, and Kumm (1981), and Faruqui and Malko (1983).

"Connecticut Light and Power Company

'Los Angeles Department of Water and Power

southern California Edison Company

${ }^{\circ}$ Carolina Power and Light Company

'Wisconsin Public Service Company

'The results for Southern California Edison reflect partial price elasticities. All others are total elasticities.

NA-Not Available

-Not statistically significant

\footnotetext{
${ }^{11}$ The obvious reason for developing a model such as this is to avoid the costly experimentation with TOU rates that a utility would have to undertake to estimate customer responses. The "transferability model" is thoroughly documented in a four-volume set (Caves, Christensen, and Herriges, 1984b and 1987).
} 
From the standpoint of experimental design, there were large differences in the five experiments. At one extreme, Connecticut Light and Power (CLP) conducted only one experiment, using a 16:1, peak:offpeak price ratio (a $15 / \mathrm{KWh}$ absolute difierential between peak and offpeak rates) with the peak period lasting four hours. The Los Angeles Department of Water and Power (LADWP), on the other hand, experimented with 40 different TOD rate structures, varying the ratio of peak to off-peak rates from 2.5 to 9.0 and the length of the peak period from three to 12 hours. The length oin the experiments also varied, from one year for CLP to three years for Wisconsin Public Service. In many cases, data dictated the methodology used to estimate the responses. Both single- and multipleequation econometric approaches were used, resulting in different types of elasticity estimates. Pre-TOD and post-TOD (before and after) data were used in some experiments, while crosssectional (side-by-side) data were used in others.

The range of estimated peak and off-peak short-run own-price elasticities for each of the five utilities presented in Table 3 resulted from either multiple experiments or multiple estimates using different estimation techniques. With the exception of the peak and off-peak partial elasticities of Southern California Edison (SCE), the elasticities in Table 3 are total elasticities, estimated by allowing income as well as price effects. ${ }^{12}$ Peak perind total elasticities vary from zero to -0.61 , the latter implying that a 10 percent increase in the peak to off-peak price ratio will lead to a 6.1 percent reduction in peak-period consumption. Similarly, off-peak total elasticities varied from negligible in the CPL experiments to -0.45 in one of the Wisconsin experiments.

In Table 3, estimates of the reduction in both $\mathrm{KWh}$ consumption and $\mathrm{KW}$ demand are presented for experiments in which those measures were calculated. Generally, the results show a fairly significant reduction in consumption (KWh) during peak hours for those residential customers placed on TOD rates, approaching a third in one CLP estimation. For SCE and WPS, the reduction was as much as one-fifth. As the discussion in the previous section pointed out, estimates of the effect of TOD rates on $\mathrm{KW}$ demand are limited by the fine level of detail required. The estimates of the reduction in KW demand in Trble 3 are projected reductions in peak demand, widely varying and as large as 70 percent for CLP. More precise estimates were not possible.

\subsection{A POOLED EXPERIMENT}

Exacerbating differences in response estimates tue to experimental design and estimation methodology are differences in characteristics of consumers and service territories for the utilities considered in Table 3. For example, it would be expected that the response to TOD rates for CPL's consumers in North Carolina with a 73 percent saturation rate of air conditioners in a climate with more than 1,000 cooling degree-days in August would be different from that of WPS' consumers with a 33 percent saturation rate and less than 400

\footnotetext{
${ }^{12}$ Different types of price elasticities can be estimated, given the available data and structure of the modeling system. Price elasticities derived from using a single-equation result in total elasticity estimates because they allow for income changes. Price elasticities estimated from demand modeling systems using an assumed functional form (such as the translog or generalized Leontief systems) are conditional on separability and homotheticity assumptions which hold total electricity expenditures constant, resulting in partial elasticities. The partial elasticities can be converted to total ones, however, given an estimate of the elasticity of electricity expenditure.
} 
cooling degree-days in August. Similarly, a three percent saturation rate for electric space heating with less than 350 heating degree-days would cause consumers of LADWP to react differently to TOD rates than WPS' consumers with a six percent saturation rate, but more than 3,000 heating degree-days in a typical cold winter month. CPL's electric water heater saturation rate of 89 percent distinguishes it from that of SCE with only one percent.

Caves, Christensen, and Herriges (1984) accounted for these differences in their pooled estimation of the five experiments, using a tiuree-stage estimating process for determining the consistency of the response, relating (1) peak to off-peak consumption, (2) weekday-to-weekend expenditures on electricity, and (3) electricity to all other expenditures in the three stages. In the first-stage substitution estimate, several important insights were gained. First, the singlemost important influence on the substitution of off-peak for peak electricity is relative prices; the higher the difference between the price of peak and off-peak electricity, the greater the substitution of off-peak for peak consumption. Also, the elasticity of substitution between peak and off-peak consumption is significantly influenced by consumer- and service area-specific factors: the types of appliances used increase the elasticity of substitution between peak and off-peak consumption, with the ownership of dishwashers in both winter and summer time periods and electric air conditioners in the summer exhibiting the strongest effects.

Table 4 quantifies some of these results; providing the elasticity of substitution of offpeak for peak electricity under different climate and major appliance-holding scenarios in summer months. ${ }^{13}$ The "typical" category represents an averige of all of the households in the five experiments. The results show that the typical consumer (in terms of major appliance holdings; has an elasticity of substitution of 0.14 between off-peak and peak consumption on a typical summer day: a 10 percent increase in the peak to off-peax price ratio leads the average consumer to substitute 1.4 percent of off-peak for peak consumption. The other results in Table 4 are intuitively appealing. Holding climate constant, the larger the number of major appliances, the greater the responsiveness to TOD rates. On the other hand, with the exception of consumers with no major appliances, the warmer the temperature, the greater the response to TOD rates. For a consumer with no major appliances, the opposite is true, suggesting tha $a_{i}$ the possession of air conditioners is significant in explaining responsiveness across weather types. Although not shown in Table 4, the estimated response of a consumer with typical appliances--except air conditioning--also declines from 0.13 in cool weather to 0.10 in hot weather.

\subsection{MANDATORY VS. VOLUNTAKY TOD RATES}

The pooled model was designed for analysis of customers on mandatory TOD rates because the experiments of the five utilities involved consumers who were either on mandatory rates or were given incentives to prevent them from self-selecting out of the experiments. Estimating the load impacts of customers on voluntary TOD rates is more difficult because of the additional problem of evaluating the decision to opt for the tariff. This latter evaluaiion is important because it determines whether the utility will benefit from

\footnotetext{
${ }^{13}$ Major" electricity-using appliances are air conditioning, space heating, water heater, range, dryer, and dishwaser.
} 
implementing the tariff. That is, if there is a tendency for volunteers to be those who already consume a relatively large share of their electricity during off-peak hours, they are more likely not to change their consuming habits, reducing the utility's net revenues in the process because of relatively lower off-peak rates.

Table 4
Customer Response to U.S. Residential TOD Rates"
Summer Months
Different Appliance and Weather Scenarios

SOURCE: Caves, Christensen, and Herriges (1984), Table 8, p. 198.

-Response measured by the elasticity of substitution between peak and off-peak electricity consumption.

Evidence on the load effects of voluntary TOD rates is somewhat sketchy. In one study, Caves, Herriges, and Kuester (1989) analyzed a voluntary residential TOU tariff offered by Pacific Gas and Electric Company (PG\&E) on an experimental basis. ${ }^{14}$ In the study, 1,000 high-volume (more than 1,000 KWh per month) volunteers were evaluated over the 1983-84 period. ${ }^{15}$ The study concluded that consumers who voluntarily select the tariff have approximately the same peak-period percentage consumption as the average residential household on PG\&E's system. Furthermore, responsiveness of customers voluntarily opting for the tariff appears to be greater than those customers on mandatory TOD tariffs. The 0.37

\footnotetext{
${ }^{14}$ PGE first offered a voluntary residential TOU tariff to its high-usage (more than $1,000 \mathrm{kWh}$ per month) customers in 1982, initially limited to 1,000 customers. In 1983, PGE was ordered to conduct an experiment to determine customer acceptance, load impacts, and cost-effectiveness of the tariffs before it could expand the program further (Keane and Goett, 1988).

${ }^{15}$ Initially, the peak to off-peak price ratio was $1.9: 1$, but was increased to $2.5: 1$ midway through 1984 . The peak period was defined over a six-hour period (12:00-6:00 p.m.) on weekdays; all other time periods considered off-peak. A two-stage estimation technique was used, modeling the decision to participate in the voluntary program in the first stage and then using those results in estimating the substitution of off-peak for peak consumption in the second stage.
} 
elasticity of substitution between off-peak and peak consumption is significantly larger than that of, for example, the 0.14 elasticity for the five utilities in the pooled study discussed above (Table 4). And, treating customers on PG\&E's voluntary tariff as if they were on a mandatory one, controlling for all conditioning variables, results in a lower elasticity of substitution ( 0.18 vs. 0.37$)$. Thus, the study suggests that more peak to off-peak response is provided by a voluntary customer, even if that customer consumes electricity under the same conditions as a similar customer on a raarıdatory TOD tariff.

In an unrelated follow-up survey of PG\&E's voluntary tariff, some reasons were provided for this conclusion. Keane and Goett (1988) concluded that a residential customer who volunteered for PG\&E's voluntary TOD rate is generally better-educated, older, has a higher income and fewer small children in tise home than the average household. Characteristics of the tariff that lure customers to volunteer include the timing of the peak period (TOD rates past 6:00 p.m. are not alluring); the alleged inequity of the customer charge for the TOD meter ( $\$ 3.00$ per month); and the perception of control that consumers have over their own electric bills by allowing them to take advantage of off-peak rates.

\subsection{USING PRICES TO IMPLEMENT OTHER DSM PROGRAMS}

The previous section showed that residential TOD rates, a specific form of the more general class of TOU tariffs, are effective in load shifting, inducing residential electricity users to switch consumption from peak to off-peak periods and, at least for a subset of low-voltage users, are cost-effective. Besides using TOD rates alone to shift load, however, Western utilities have used other forms of TOU tariffs in conjunction with other DSM programs to manage low-voltage electric load. For winter-peaking utilities in which electric space heating causes the low-voltage peak, for example, thermal energy storage (TES) systems promoted in conjunction with TOD rates have also proved successful in shifting consumption from peak to off-peak periods, especially in Western Europe. The cost-effectiveness of TES systems for space cooling, however, is questionable. What has proven successful for summer-peaking utilities where air conditioners are the causal factor, however, are cycling programs promoted by a TOU rate incentive. In these programs, the primary load objective is generally peak clipping, rather than load shifting. TES and cycling programs will be discussed in turn.

British and German utilities have pioneered the use of TES programs for space heating, implemented by TOD pricing, significantly improving their winter residential load factors in the process. Beginning in 1961, area electricity boards in England and Wales, promoted (off-peak) storage radiators for residential heating with a 2:1, peak:off-peak price ratio. Fourteen years after introduction of the tariff, a load study showed the long run effect, summarized in Table 5 for homes using direct-resistance heating, high-capacity storage radiators, and central storage heating (a central heating system using a storage heater and forced-air distribution). The table suggests that normally insulated homes converting from direct resistance heating to one of the thermal storage types switch approximately 50 percent of their electricity consumption from peak to off-peak periods. For highly insulated homes, the percentage switch is dramatic, but not as great as that of normally insulated ones. As for the entire residential load, storage heating shifts 2000 to $3000 \mathrm{~mW}$ of load out of the daytime for an average winter day and, on the coldest days, the amount of the shift is as high as $10,000 \mathrm{~mW}$ (Mitchell, Manning, and Acton, 1978). The impact on load shifting of a storage heating promotion program initiated in 1964 by several utilities in West Germany are similar 
to that of England and Wales. From 1964 to 1974, total electricity consumption in West Germany increased 109 percent, while peak load increased only 84 percent; total-system load factor in mid-December increased from 77 to 88 percent.

Table 5
$\begin{aligned} & \text { Percent of Residential Electricity Consumption in Off-Peak Hours } \\ & \text { By Type of Heating System } \\ & \text { England and Wales } \\ & 1975 \\ & \text { (In Percentages) }\end{aligned}$

SOURCE: Mitchell, Manning, and Acton (1978), Table 30, p. 126.

Use of TES for residential space cooling, on the other hand, is not as widespread. While some commercial and industrial customers have taken advantage of low electricity prices during off-peak periods to create ice and use it for cooling during on-peak periods during the daytime, the technology has not gained wide acceptance by low-voltage users. Indeed, test results on residential cool storage systems at five U.S. utilities suggest that commercialization of TES for air conditioning is not yet cost-effective for either the utility or the residential consumer (Oak Ridge National Laboratory, 1983). Later studies showed similar results. Brown and Spanner (1989), for example, concluded that residential TES cooling systems currently would require significant financial incentives from the utility to be cost-effective. Their conclusion is based on analysis of three building types (ranch, two-story, and townhouse) in three U.S. cities (St. Louis, Pittsburgh, and Hartford) where the electric utilities have implemented TOD rates for low-voltage users.

In contrast to TES programs, the purpose of which is to shift electricity consumption from peak to off-peak periods, load management programs have also been implemented by Western utilities to shed peak load. Many variants of these programs have been implemented: (1) different types of end uses under control; (2) varying load control responsibility (customer vs. utility); and (3) different types of communication systems (if the utility has control over the load). 
Although water heaters, space heaters, irrigation pumps, and air conditioners have been the objects of control in U.S. load control programs, the most successful have been associated with air conditioning because of its large contribution to the system peak of many utilities. And, rather than relying on customer (voluntary) control of the load using such devices as time clocks, thermostats, current limiters or interlocking devices preventing two or more appliances from coming on at the same time, the most effective programs have proved to be those giving the utility control over the load (direct load control). A typical direct control air conditioner program involves cycling air conditioners on and off during the course of days when the power system is approaching maximum capacity, usually for a maximum number of hours and days during the summer peaking season, using a form of TOU pricing to attract customers to participate in the programs. The types of communication systems include the power line carrier itself, telephone, and radio.

In the United States, air conditioner cycling programs have been estimated to lead to peak-day demand reductions on the order of $1.5 \mathrm{KW}$ per customer. As a specific example, the air conditioner cycling program implemented in 1983 at Southern California Edison, a large summer-peaking U.S. utility, uses remote radio signals to cycle central air conditioners for a maximum of six hours per day, over a maximum of 15 days, from June through September. The financial incentive is based on the percentage of time which consumers agree to have their air conditioning systems cycled off during those days, up to the six-hour, 15-day maximum. On peak days when the temperature approaches 103.2 degrees $F$, peak load is reduced on average by $1.7 \mathrm{kw}$ per customer, while total $\mathrm{KWh}$-consumption for participating consumers is reduced by less than $0.5 \mathrm{KWh}$ (Noell, 1989). 


\section{RESPONSE TO TOU RATES: HIGH-VOLTAGE USERS}

For many utilities, an inviting target for DSM measures is the high-voltage, industrial sector because it is typically the largest sectoral consumer of electricity and has the highest amount of per-consumer usage. In Western economies, the latter characteristic has facilitated direct contact between individual electricity users and the utility for technical, non-price DSM programs: assistance with managing energy use (e.g., industrial conservation progranss) and advice on generating at least a portion of their own electricity needs (e.g., cogeneration and waste heat recovery). Adoption of any of these programs by industrial users, of course, hinges on inrentives and cost-effectiveness.

With regard to using a more indirect pricing approach as a DSM strategy, the most widely adopted form of innovative pricing to change the pattern of industrial electricity consumption is TOU pricing. Evidence on the extent to which TOU pricing has been adopted by U.S. utilities for industrial consumers is presented in Table 6, documenting the results of two surveys of U.S. investor-owned utilities on the types of industrial rate structures implemented in 1983 and 1986. Although the surveys suggest that these utilities have implemented many different types of rate structures, the most widely adopted one is time-ofuse (TOU) pricing ( 72 percent of the utilities in 1986, up from 55 percent in 1983), which, for purposes of the surveys, was narrowly defined to refer to rates which vary hour-by-hour over the course of the day. In this paper, TOU rates are defined more generally to refer to rates which vary over any period of a year: hour-by-hour, day-by-day, or season-by-season. Using this definition, the second most prominent tariff used by U.S. utilities is nother form of a TOU tariff, an interruptible or curtailable (I/C) one, used to reduce demand on days when capacity utilization is approaching its limit, usually offering rate incentives to consumers in return for shedding load for a limited amount of time on short notice. ${ }^{16}$ Table 6 shows that usage of this type of TOU tariff by U.S. utilities increased from 54 to 65 percent over the three-year period.

Western European utilities have also been very active in using TOU rates in the industrial sector as a DSM strategy. France, for example, has been a leader in implementing innovative rate structures for large-volume users as a DSM strategy. Electricite de France developed marginal cost price schedules for high-voltage users as early as 1955 , implementing voluntary industrial TOD rates for high-voltage users in 1958. A decade later, the tariff was made mandatory. Besides the early French experience, TOU pricing has been used extensively on both hydro- and thermal-dominant power systems in Western Europe. A seasonal tariff for high-voltage users reflecting the seasonality of water supply has long characterized the hydro-based Norwegian power system in which there is a greater tendency for seasonal rather diurnal changes in operating costs. At the other extreme, the thermaldominant British system has long had optional high-voltage TOD tariffs in effect. Also, the peak-period warning tariff, a type of $\mathrm{I} / \mathrm{C}$ rate, applies for a maximum of 60 hours during a four-month peak period from November through February.

\footnotetext{
${ }^{16}$ An interruptible tariff implies that the customer must reduce consumption entirely, while a curtailable rate implies that the consumer must reduce consumption to some agreed upon level, not necessarily totally.
} 
Table 6

Implemented Electricity Tariffs in the

U.S. Industrial Sector Survey Results"

1983 and 1986

\begin{tabular}{|c|c|c|c|c|}
\hline \multirow{2}{*}{ Type of Rate } & \multicolumn{2}{|c|}{1983} & \multicolumn{2}{|c|}{1986} \\
\hline & Number & $\%$ & Number & $\%$ \\
\hline Time-of-Lise & 67 & 55 & 79 & 72 \\
\hline Interruptible/Curtailable & 66 & 54 & 72 & 65 \\
\hline Industrial Incentive/Economic Development & 11 & 9 & 28 & 25 \\
\hline Inverted Block & 1 & 1 & 1 & 1 \\
\hline Special Purpose Incentive & 11 & 9 & is & 12 \\
\hline Vintage & 1 & 1 & 0 & 0 \\
\hline Demand Subscription & 0 & 0 & 1 & 1 \\
\hline Partial Requirement & 19 & 15 & 35 & 32 \\
\hline Other & 3 & 2 & 6 & 5 \\
\hline
\end{tabular}

SOURCE: Ebasco Business Consulting Company $(1985,1988)$.

"For the 1986 survey, 156 investor-owned utilities were surveyed; 110 (more than 70 percent) responded. The corresponding numbers for 1983 were 157 and 123 (more than 75 percent).

${ }^{b}$ For purposes of the survey, the rates were defined as follows: Time-of-Use: a rate varying by usage during the day; Interruptible/Curtailable: a rate giving credit to reduce usage to some prearranged level upon notification from the utility; Industrial Incentive/Economic Development: a rate keeping industrial customers on the grid or attracting new customers. Inverted Block: A rate in which the demand or energy charge increases with usage. Special Purpose Incentive: a rate providing a credit for participating in a utility program (e.g., air-conditioner cycling, conservation). Vintage: a rate in which historic consumption is priced differently than new consumption. 'Demand Subscription: a rate in which a customer receives a rebate for subscribing to a maximum level of demand which never can be exceeded because electric service is shut off. Partial Requirement: a rate, different from the standard one, applying to consumers who purchase only a portion of their power needs from the utility (e.g., cogenerators).

TOD pricing used alone as a load management strategy for high-voltage consumers has been effective in shifting electricity consumption from peak to off-peak periods for the higher-voltage customer class a whole, but a question remains about the extent of that shift. There are widely varying estimates of the own-price elasticity of demand for peak-period electricity in both TOD experiments and mandatory TOD tariffs implemented at individual U.S. utilities. These studies, however, used varying methodologies and types of data, and were limited to individual utilities. A more recent study involving ten geographically diversified utilities showed that the response of commercial and industrial customers is fairly wiv." when mandatory TOD rates are first implemented: a one percent change in peak-period consumption. However, estimates of high-voltage consumer response to TOD rates represent the short run: the data were not of sufficient length to capture changes in the stock of energy 
durables in response to the tariffs. In a less precise estimate of long run industrial response to the French TOD tariff using load curve analysis, 24 percent of the 444 firms under scrutiny exhibited a significant response to TOD rates as reflected by their load curves (Acton and McKay, 1984).

The more important conclusion to be drawn from this experience for countries considering TOD pricing as a load management strategy is that all of the studies showed wide variability of response by individual industries. Generally, energy-intensive, mechanical production processes, whose load is easily curtailed (such as cement production), are more responsive to TOD rates than, say, continuous process industries which find it more difficult to curtail production during peak periods and/or shift production to off-peak periods.

The remainder of this section explores these conclusions in more detail, first looking at the experience of U.S. utilities with TOD rates and then turning to the evidence on individual industries in Section 4.2 and then to the effect of interruptible/curtailable tariffs in Section 4.3.

\subsection{AGGREGATE RESPONSE TO TOD RATES ACROSS INDUSTRIES}

Table 7 summarizes four studies of higher-voltage response to TOD rates, two each (small and large maximum demand) at two large U.S. utilities in California: Pacific Gas and Electric Company (PG\&E) and Southern California Edison Company (SCE). The two highvoltage studies resulted in very different estimates of the own-price, peak period elasticity of demand: PG\&E's estimated elasticity of -0.087 is much larger than the -0.018 estimated for winter peak-period energy at SCE. ${ }^{17}$ One explanation is the different methodological approaches used to derive the estimates. While both studies employed a translog specification, the estimates for PG\&E did not distinguish between the demand and energy charge, instead assuming that they were proportional, while the $\mathrm{S} \cup E$ study explicitly accounted for the differences.

Also, using the translog specification in allocating expenditure shares to different periods may not be appropriate for analyzing customer response to TOD rates; there is evidence that a response is shown when none exists (Acton and Park, 1987). Indeed, in his analysis of PG\&E's smaller-voltage consumers, Woo (1985) compared a generalized Leontief expenditure-share function with that of the translog and found that the latter generally led to larger elasticities. With an 8:5:1 peak:shoulder:off-peak price ratio, for example, the Leontief form resulted in a peak-period price elasticity of -0.019 in comparison with -0.088 for the translog.

In comparing the two studies of commercial-small industrial $(<500 \mathrm{KW}$ in maximum demand) response to TOD rates, differing results also emerge. In the PG\&E experiment in

\footnotetext{
${ }^{17}$ Different price elasticities can be estimated, given the avallable data and structure of the modeling system used to estimate them. Price elasticity estimates derived from demar hodeling systems using an assumed functional form (such as the translog or generalized Leontief systems, re conditional on separability and homotheticity assumptions which hold total electricity expenditures constant, resulting in partial price elasticities of demand, which is the case for both the PG\&E and SCE studies. The partial elasticities can be converted to total ones, however, given an estimate of the electricity expenditure elasticity.
} 
which only energy charges were applied (no demand charges) and the Leontief functional form was used, TOD rates led to small reductions in peak-period $K W h$ consumption. In the SCE study using a constant elasticity of substitution functional form, energy charges were not effective in shifting $\mathrm{KWh}$ consumption from peak to off-peak periods.

Table 7

Summary of Four Studies of U.S. Response to High-Voltage TOU Rates

Utility/Maximum Demand Customers Approach Results

Pacific Gas and Electric:

$\begin{array}{llll}>4 \mathrm{~mW}^{\bullet} & 64 & \text { Translog } & \text { High elasticity } \\ <500 \mathrm{KW}^{\mathrm{b}} & 560 & \text { Leontief } & \text { Low elasticity } \\ & & \text { Translog } & \text { High elasticity }\end{array}$

Southern California Edison:

$\begin{array}{llll}>5 \mathrm{~mW}^{\mathrm{c}} & 104 & \text { Translog } & \text { Low elasticity } \\ <500 \mathrm{KW}^{\mathrm{d}} & 650 & \text { CES } & \text { Demand rate effective }\end{array}$

'Chung and Aigner (1981). Mandatory TOD tariff implemented in February 1977 with peak, intermediate, and off-peak periods, summer-winter seasonal components (six-hour peak in summer and four-hour peak in winter), and both demand and energy charges. The study used $31 / 2$ years of data from October 1975 (before implementation of the tariff) to February 1979.

'Woo (1985). Three-year experimental TOD tariff implemented in January 1981 with four experimental rate schedules and onty energy charges. The stucty used four months of data from May to August 1982.

THirschberg and Aigner (1983). Mandatory TOD tariff implemented in October 1977 with peak, intermediate, and off-peak periods, summer-winter seasonal components (six-hour peak in summer and five-hour peak in winter), and both demand and energy charges. The study used 5 years of data from 1976 (before implementation of the tariff) through 1980.

${ }^{d}$ Ajgner and Hirschberg (1985). Two-year experimental TOD tariff implemented in January 1981 with six experimental rate schedules: two schedules (constant energy charge/variable demand and variable energy/constant demand) with three different rate structures varying by peak to off-peak charges within each.

In a more comprehensive study, Park and Acton (1984) and Acton and Park (1987) broadened the scope of these single-utility studies to include 10 geographically diversified U.S. utilities. $^{18}$ Using hourly load data ranging from $21 / 2$ to 6 years for more than 6,000

\footnotetext{
${ }^{18}$ Three of the utilities were from California (Southern California Edison, Pacific Gas and Electric, and Los Angeles Department of Water and Power), two form New York (Consolidated Edison and Long Island Lighting), and five from the Midwest (Wisconsin Electric Power, Madison Gas and Electric, Wisconsin Power and Light, Commonwealth Edison, and Consumers Power).
} 
customers on mandatory TOD rates, the authors estimated changes in relative load for (1) introducing TOD rates, (2) continuing the standard tariff, and (3) continuing TOD rates, based on characteristics of the tariff (price ratio and hourly length of the pricing periods) and conditioning factors such as the weather, location, and customer size. ${ }^{19}$ Table 8 presents the percentage change in relative $\mathrm{KWh}$ consumption and $\mathrm{KW}$ demand for the three periods upon introduction of TOU rates, divided between commercial, industrial, and total responses.

\begin{tabular}{ccc} 
& Table 8 \\
& $\begin{array}{c}\text { Change in Relative Loads" } \\
\text { Introduction of TOU Rates } \\
\text { U.S. High-Voltage Consumers } \\
\text { (In Percentages) }\end{array}$ \\
\hline Period & Commercial Industrial & Total \\
\hline
\end{tabular}

KWh Consumption:

$\begin{array}{lcrr}\text { Peak } & -0.29 & -1.03 & -0.84 \\ \text { Shoulder } & 0.00^{*} & 0.21 & 0.19 \\ \text { Off-Peak } & 0.39 & 0.50 & 0.47\end{array}$

KW Demand:

\begin{tabular}{lclc} 
Peak & -5.16 & $0.89^{*}$ & $-0.73^{*}$ \\
Shoulder & $0.86^{*}$ & 2.46 & 2.30 \\
Off-Peak & -2.05 & 1.08 & $0.24^{*}$ \\
& & & \\
\hline
\end{tabular}

SOURCE: Acton and Park. (1987), Tables 12 and 14.

'Statistically insignificant.

'Relative KWh consumption for any of the three periods is defined as the average $\mathrm{KWh}$ consumption during the period expressed as a percentage of average KWh consumption during all weekday hours. Similarly, relative KW demand for any of the three periods is the ratio of maximum hourty demand during any of the periods to the average hourly $\mathrm{KWh}$ consumption during that period. Both $\mathrm{KWh}$ consumption and KW demand were measured as changes from the preced. ing year.

For KWh-consumption, changes in relative load for peak and off-peak consumption are significant and of the correct sign: consumption decreases on the peak and increases off-

\footnotetext{
${ }^{19}$ The 1987 study expanded the one conducted in 1984 by including (1) all months of the year instead of just June and November, (2) shoulder and off-peak as well as peak period responses, and (3) relative kw-demand as well as relative $\mathrm{kWh}$-consumption for each of the three periods.
} 
peak as a result of changing relative prices during these periods. The amount of change during both periods, however, is small. Total peak period relative load changed by less than one percent, with the commercial sector showing the lowest response. Off-peak consumption, on the other hand, increased less than one-half percent, with commercial and industrial response nearly the same. There is no a priori speculation on changes in shoulder periods-relative loads can increase or decrease--and the ten-utility sample suggests changes are very small for both commercial and industrial customers.

For $\mathrm{KW}$ demand, the results are less conclusive. The change in total relative $\mathrm{KW}$ demand for both peak and off-peak periods has the correct sign but is not statistically significant for both periods. Although also not statistically significant, the direction of change in relative $\mathrm{KW}$ demand during the peak period for the industrial category is the reverse of what is expected. One plausible explanation for this inconclusiveness is the measurement of peak load, which is only a proxy for instantaneous demand during these periods (Footnote a, Table 8).

\subsection{RESPONSE TO TOD RATES BY INDIVIDUAL INDUSTRIES}

Although the estimated change in aggregate KWh consumption was small, the Acton and Park (1987) study showed a significant variability for individual industries. Wood products, Standard Industrial Classification (SIC) 24, for example, showed the largest response of any individual industrial category with a 6.38 percent change in relative consumption. In Chung and Aigner's (1981) study of large-voltage customers at PG\&E in which the mean peak elasticity of demand was estimated to be -0.087 for all industries in total, the estimated elasticity for logging camps (SIC 2421), a subset of SIC 24, was -0.152. Another good example is cement production. While the Acton-Park estimate of change in relative load for the aggregate category Stone, Clay, and Glass (SIC 32) was only 1.59 percent, a little above the average of all industries, the Chung-Aigner estimate of -0.227 for SIC 3241, hydraulic cement production, a subset of SIC 32, was the largest estimated response for any of the industries in that study.

There is also evidence from studies of the impact of Western European TOD tariffs that the response for many of these same industries is significant. And, in contrast to the U.S. estimates, those responses are long run. French cement producers who have been on TOD rates since the 1950 s, for example, exhibited significant response to TOD rates. In a load shape analysis of French cement and limestone producers, Acton and McKay (1984) showed that, out of 32 firms under consideration, 82 percent exhibited significant response to TOD rates as evidenced by changes in their load curves. For all of French industry, only 24 percent (of the 444 firms under consideration) exhibited similar characteristics.

Figure 3 characterizes the response of a large French cement plant to TOD tariffs during a typical winter week, confronting 14.3:5.7:1 and 3.2:1.9:1 peak:shoulder:off-peak relative prices for demand and energy charges, respectively. During peak-period hours ( 7 a.m. to 9 a.m. and 5 p.m. to 7 p.m.), the French cement maker reduces its load by 50 percent; however, on Sundays when off-peak tariffs exists, cement use is at the same level as that of the highest during off-peak periods on weekdays. A similar response was observed for the average load curves of cement producers in two French industrial areas (Mitchell, Manning, and Acton, 1978).

Even though the British large-voltage TOD tariff differs significantly from that of the French tariff (voluntary TOD rates over a 10-hour peak period in winter months with only a 2:1 peak:off-peak price ratio), British cement producers respond similarly to those of the French, representing the largest response of all of the British industries to TOD rates. A 
typical British cement producer reduces load by 50 percent during the 10-hour peak on weekdays and, similar to the French cement producer portrayed in Figure 3, consumes electricity at virtually a constant rate on Sundays at the highest level of off-peak, weekday consumption.

Figure 3

\section{Load Curves for a French Cement Plant}
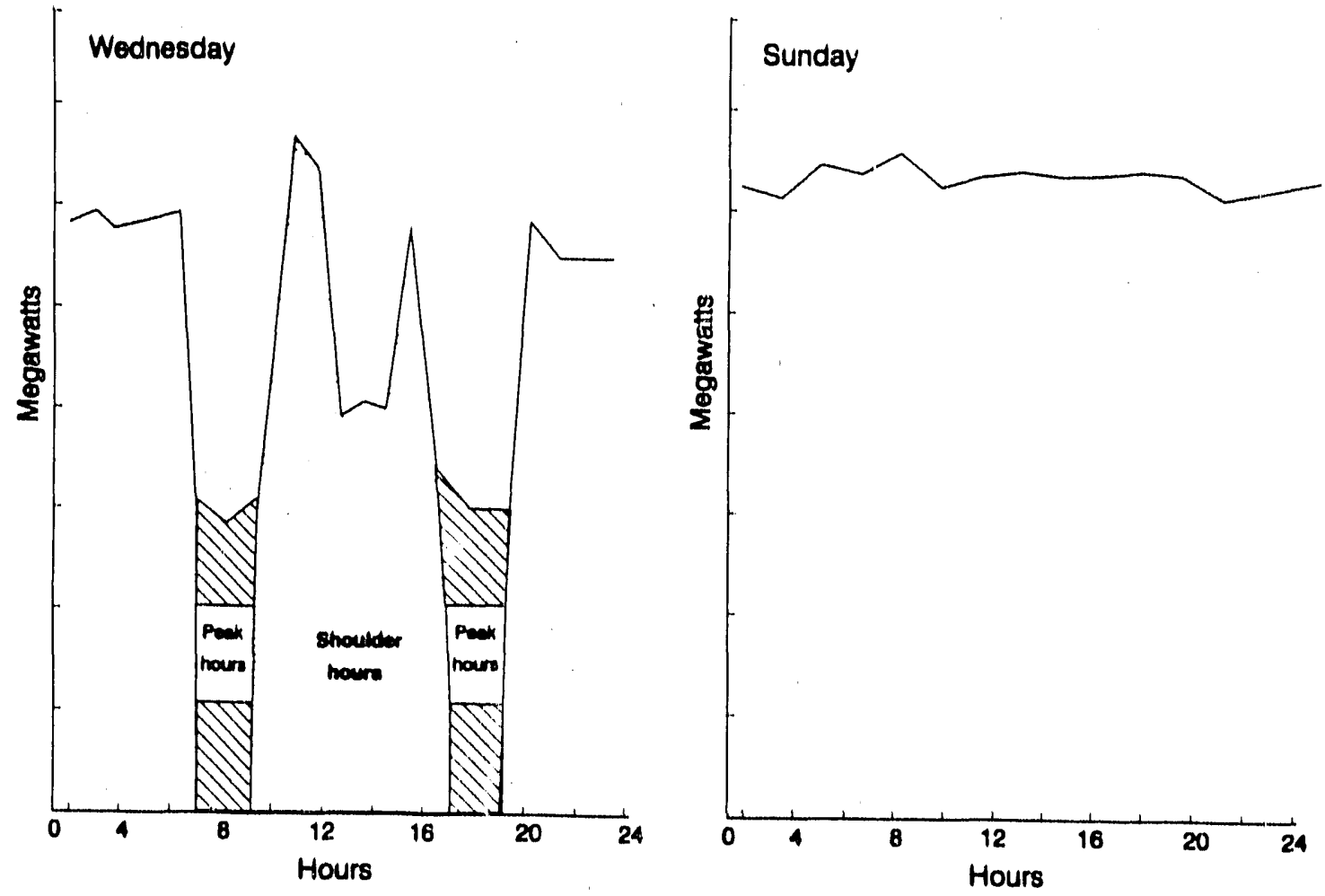

SOURCE: Mitchell, Manning, and Acton, 1978, Figure 17, p. 92.

Another industry that is amenable to reducing loads quickly is liquid and gas transportation by pipeline. In the French load curve analysis, Mitchell, Manning, and A.cton (1978) found that, besides cement producers, petroleum pipelines demonstrated the most significant reduction in electricity use during peak periods. Of the 28 pipelines considered, 79 percent exhibited significant reductions in response to TOD pricing. Figure 4 presents the load curve of a French petroieum pipeline which, similar to the cement producer depicted in Figure 3, is able to significantly reduce load during the two peak periods during the week and yet maintain a constant load during the off-peak weekend period. 
Figure 4

Load Curves for a French Petroleum Pipeline
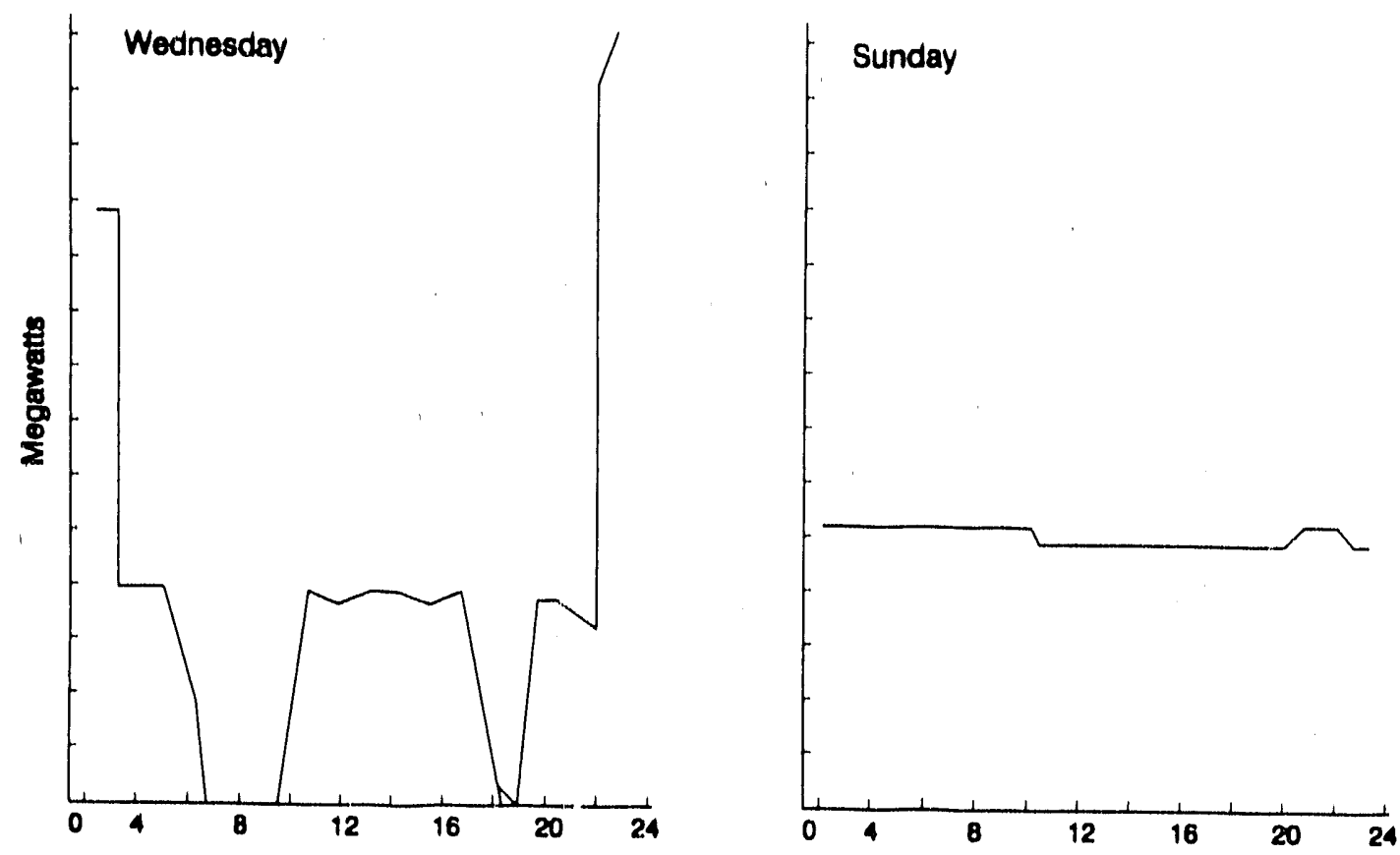

SOURCE: Mitchell, Manning, and Acton, 1978, Figure 17, p. 92.

In contrast, continuous process industries exhibit some of the lowest elasticities in studies of U.S. responsiveness and show the least responsive load curves in studies of Western European industries. A good example is motor vehicle production. While the industrial classification is somewhat aggregated, Acton and Park's estimated change in relative load for transportation equipment (SIC 37) was only a quarter of a percent, one of the lowest estimated responses for any of the industries. At a somewhat more disaggregated level, Chung-Aigner's peak-period price elasticity estimate of -0.064 for motor vehicle production (SIC 3711) is one of the lowest in their 13 industrial classifications. For a longer run perspective, 17 of the 19 firms involved in automobile and cycle production in Mitchell, Manning, and Acton's (1978) study of French industrial response to TOD rates were "daypeaking:" above-average consumption in peak hours and below-average in off-peak hours.

Petroleum refining is another continuous process industry which exhibits little response. In the Acton-Park study, the change in relative load for the aggregated petroleum industry (SIC 29) was not significant. In the Chung-Aigner study, the peak-period elasticity 
of demand for petroleum refining (SIC 2911) was only -0.059. In the study of longer run responses of French industries by Mitchell, Manning, and Acton, however, the response is mixed. Nearly one-half of the 21 refineries showed virtually no response to TOD tariffs, six responded significantly, and four had above average usage. A contributing factor to this pattern in the petroleum refining industry is the amount of self-generation, which allows some refineries the ability to substitute their own self-generated power for higher-cost utility power during peak periods. In this regard, any firm which has its own source of power--using waste heat, steam, or gases, besides their own thermal units-- or has a duel-fuel capability is likely to be more responsiveness to TOD rates than firms which do not.

\subsection{THE EFFECT OF INTERRUPTIBLE/CURTAILABLE TARIFFS}

In contrast to TOD rates which are aimed at shifting peak-period electricity consumption to off-peak periods, interruptibie/curtailable (I/C) tariffs have been widely used by Western utilities to shed peak electric loads and, from every indication, they have been successful. Although there are probably as many variants of the tariff as there are utilities using them, they are more frequently offered to higher-volume, larger-voltage users, giving these customers a credit on their utility bills for reducing consumption to some agreed upon level when notified by the utility that it is approaching conditions of maximum demand, typically with very little advance warning (from as little as 15 or $\mathbf{3 0}$ minutes to as long as 24 hours) for a maximum number of hours during the year. In some cases, the utility controls the load of the consumer, thus ensuring compliance with terms of the agreement. In other cases in which individual consumers control their own loads, the penalty for consuming at levels above those agreed upon varies from contract to contract.

A study by Caves, Hanser, Herriges, and Windle (1988) of 147 customers under I/C tariffs at 10 U.S. utilities showed that there was a significant reduction in load for utilities offering the I/C tariff (Table 9). The reduction varied from as little as $300 \mathrm{KW}$ per customer for one of the utilities to nearly $14 \mathrm{~mW}$ for another w! ich enlisted only its largest industrial customers for the tariff. Also, the results showed that the tariff was effective in reducing most of the utilities' loads to the agreed upon level. For eight of the utilities which offered I/C rates requiring customers to reduce load to some level greater than zero during interruptible periods, all of the utilities with the exception of one equalled or exceeded their required load reduction, with one utility obtaining 138 percent of its required load relief. The other two utilities attained 80 and 99 percent of their required load reduction. ${ }^{20}$

An interesting aspect of $\mathrm{I} / \mathrm{C}$ tariffs is that the load factor of electricity users--the ratio of average to peak load--plays a significant role in the amount of response to I/C rates, stemming from the manner in which the credit is given for inducing consumers to lower their consumption during the interruptions. Typically, the financial incentive is a $\$ / K W$ credit based on the difference between a customer's maximum non-coincident peak demand and its agreed upon, reduced power level during an interruption. Therefore, there is a stronger incentive for low load factor customers to subscribe to an interruptible tariff because the

\footnotetext{
${ }^{20}$ The percentage of required load reduction is defined as the ratio of the actual reduction in load during an I/C period (defined as the difference between the forecast of consumption in the absence of an $\mathrm{I} / \mathrm{C}$ rate and actual consumption) to the required reduction (forecasted power level less agreed upon, reduced level).
} 
chances that their peak 'Jads coincide with the interruptible period are smaller. The drawback for the utility is that customers with lower icad factors will contribute less to load reductions during the interruptible period than higher load factor customers, even though they will be credited with higher amounts of load reduction.

Table 9

Customer Response to Interruptible/Curtailable Rates

Ten U.S. Utilities

\begin{tabular}{ccc}
\hline Utility & $\begin{array}{c}\text { Actual } \\
\text { Load } \\
\text { Reduction } \\
(\text { MW })\end{array}$ & $\begin{array}{c}\text { Required } \\
\text { Load } \\
\text { Reduction } \\
\text { (\%) }\end{array}$ \\
\hline 1 & 125 & 99 \\
2 & 14 & 130 \\
3 & 50 & 138 \\
4 & 19 & 109 \\
5 & 92 & 102 \\
6 & 33 & $99^{c}$ \\
7 & 64 & 129 \\
8 & 1 & $80^{c}$ \\
9 & 69 & 129 \\
10 & 33 & 100 \\
& & \\
\hline
\end{tabular}

SOURCE: Caves, Hanser, Herriges, and Windle (1988), Tables 1 and 2.

"Average hourly load relief for each utility.

Percentage of required load reduction, defined as the ratio of the actual reduction in consumption during an I/C period (defined as the difference between the forecast of consumption in the absence of an $\mathrm{V} / \mathrm{C}$ rate and actual consumption) to the required reduction (forecasted less firm power level). With the exception of utilities $F$ and $H$, the results reflect utilities with firm power levels greater than zero. Since all utilities in $F$ and $H$ have FPLs equal to zero, the maximum reduction is 100 percent.

Teflects utilities which all bave FPLs equal to zero.

This was shown in the Caves et al. (1988) study. Table 10 quantifies the phenomenon, providing the ratio of credited relief to actual relief for customers at the ten utilities under two computations of load factor. The results show that customers with lower load factors are credited with more load reduction than customers with higher load factors. On average, all customers are credited with twice the amount of load reduction than the utility actually experiences. For customers with load factors less than 25 percent, the credit was approximately 5-to-1, while for high load factor customers, the credit was only 1.2-to-1. 
Table 10

Summary of Credited Relief under U.S. Interruptible/Curtailable Rates

By Load Factor

\begin{tabular}{llllll}
\hline & \multicolumn{5}{c}{ Load Factor } \\
\cline { 2 - 6 } Load Factor Calculation & $0-25$ & $25-50$ & $50-75$ & $75-100$ & All \\
\hline & & & & & \\
Peak Load Factor & 5.68 & 4.30 & 2.05 & 1.27 & 1.97 \\
Annual Load Factor & 4.49 & 3.82 & 1.84 & 1.20 & 2.00 \\
\hline
\end{tabular}

SOURCE: Caves, Hanser, Herriges, and Windle (1988), Table 3.

Various forms of the interruptible tariff have also been widely used by Western European utilities to shed load during system peak hours. A good example is the peak-period warning (PPW) tariff in England and Wales. The tariff applies for a maximum of 60 hours during a four-month peak period from November through February. The central generating board notifies its participating large-volume customers of a projected shortage in generating capacity a day in advance. The penalty for not reducing load to the agreed upon level is an extremely high demand charge. Under the tariff, participating customers shed nearly 40 percent of their load during the PPW periods, representing approximately 11 percent of the total industrial load (Mitchell, Manning, and Acton, 1978). 


\section{COST-EFFECTIVENESS OF TOD PRICING}

\subsection{SUMMARY}

Estimated responsiveness to TOD rates, measured by the price elasticity of demand, is a prerequisite for conducting a cost-benefit analysis, the determining factor in deciding whether the benefits of of implementing a TOD rate structure outweigh the costs of implementing it. One of the most important additonal costs in moving to TOD rates is metering costs, including the cost of the meter and the administrative costs of monitoring the rates. For low-voltage users, evidence on the cost-effectiveness of TOD rates is much less clear because metering costs represent a large portion of the total cost of supplying individual electricity consumers. For large-voltage users, however, additional metering costs do not appear to be prohibitive bezause these costs are such a small portion of the total costs of supplying individual consumers. In their study of more than 6,000 commercial and industrial customers at ten U.S. utilities, Park and Acton (1984), for example, concluded that TOD pricing results in a net welfare gain of $\$ 1,000$ per customer per annum, assuming no net change in electricity consumption (consumption reductions on the peak were assumed to be offset by additions offpeak). And, assuming metering costs of less than $\$ 65$ per year, the welfare gain is more than $\$ 900$ per customer per year.

The cost-effectiveness of TOD rates for low-voltage users is an important issue because metering costs represent a large portion of the total cost of supplying individual electricity consumers. Based on the evidence from the U.S. residential TOD pricing experiments, the higher the level of consumption by the average consumer under TOD tariffs, the greater the likelihood that the tariff will prove cost-effective, or, at least, will be less costineffective than lower average consumption levels. The higher the ratio of peak to off-peak prices, the more likely the tariffs will also prove to be cost-effective. Finally, summer peaking utilities with air conditioners as the main peaking cause appear to benefit more from residential TOD rates than utilities which are in cooler climates. These results are generally based on estimates of short-run responses to TOD rates; to the extent that longer run responses are larger, the tariffs should be cost-effective for a much larger class of low-voltage consumers.

\subsection{CONCEPTUAL ISSUES}

These general conclusions on the cost-effectiveness of TOD tariffs, however, are clouded by questions of perspective. Conceptually, the cost-effectiveness of TOD pricing is determined by comparing the incremental discounted benefits of adopting the rate structure with its associated discounted costs, using an appropriate discount factor (e.g., the utility's opportunity cost of capital). In actual practice, however, determining the cost-effectiveness of residential TOD pricing--or any other DSM option--depends on perspective: (1) the viewpoint of the party making the cost-benefit determination and (2) the categories of costs and benefits included in the calculus, which generally include three broad categories:

1. Net benefits to electricity consumers,

2. Net benefits to electric utilities, and

3. Other net benefits, the value of which are not market-determined. 
As for the first perspective, an economist and utility practitioner do not necessarily view the net benefits of TOD tariffs in the same way. Typically, a utility is more interested in the second category of costs and benefits: net revenues and cash flow. That is, the effect of a TOD tariff on the "bottom line" and cash flow are generally the most important aspects in considering a move to TOD rates. Other than estimates of the impact of consumers' response on its revenues, the consumer and society at large are generally not of paramount importance.

To illustrate the point, a widely used framework for determining the cost-effectiveness of DSM options, including TOD pricing, developed by the California Public Utilities Commission and California Energy Commission (1987), provides four tests--or perspectives--to be included in the cost-benefit determination:

1. Participants Test, which measures the net financial impact on consumers participating in the DSM program (e.g., effect on utility bills, out-of-pocket expenses for participation);

2. Ratepayer Impact Measure, formerly called the nonparticipants test, which quantifies the impact of a DSM option on the net revenues of the utility (change in revenues and change in costs);

3. Total Resource Cost Test, which is essentially the net of the first two: the reduction in utility bills and any incentive payments to consumers are offset by the reduction in utility revenues and the cost of the incentive payments to utilities; and

4. Utility Cost Test, formerly called the Utility Revenue Requirements Test, because it measures the change in costs to the utility as a result of the program and, hence, the change in required revenues for the utility.

Each of the tests serves a different purpose and none is recommended as the test for adopting any DSM alternative.

From an economic standpoint, cost-effectiveness is more arcane, suggesting that evaluating a movement to TOD rates should be based on welfare criteria, including both the net impact on the utility's revenues resulting from the tariff (such as the ratepayer impact measure) but also changes in the value of service to consumers. In practice, changes in the value of service resulting from TOD rates are measured by estimating compensating (or equivalent) variation: the change in income that has an equivalent effect on consumers' satisfaction (i.e., utility) as the change in electricity prices.

Another complicating factor recognized by the authors of these four tests (and included as a variant of their Total Resource Cost Test) is the net benefits, which are difficult to quantify in many cases because their value is not generally determined by market forces. These categories of costs and benefits can affect an individual consumer (e.g., inconvenience caused by an air conditioner cycling program), a region, a nation as a whole, or even have global repercussions. Many of these costs and benefits also have multiple effects. For example, the macroeconomic effects of a demand-side option may have regional and national employment effects. For smaller economies, the effect of reducing petroleum requirements for a single generating station could have significant foreign exchange implications. Related, a demand-side option reducing imported petroleum requirements increases energy security. The environmental impacts of using the demand side as a source of resources--in comparison 
with building additional electric generating capacity using fossil fuels--has important implications for the regional, national, and global environment.

Many of these "externalities" are difficult to quantify, of course, but some are increasingly considered--at least qualitatively--in determining the cost-effectiveness of any resource option being considered by electric utilities as governments and the public become more aware of their consequences (e.g., the environmental effects of using fossil fuels for power generation). What is often overlooked in cost-benefit studies, however, is the effect of a resource option on the value of service to consumers, which can be substantial, especially for TOD pricing.

To illustrate this, Table 11 presents the results of a study comparing different methodologies for estimating the cost-effectiveness of TOD rates for Central Illinois Light Company, one of four electric utilities in Illinois for which the feasibility of TOD rates was evaluated. ${ }^{21}$ The table shows the present value of net benefits before metering costs (and after, which are the same under any of the methodologies). ${ }^{22}$

For the consumer, the "welfare" measure represents an estimate of equivalent variation: the change in income that would have the same effect on consumer satisfaction as the change to TOD prices. The "surplus" measure for the consumer is simply the change in consumer surplus as a result of the change to TOD pricing. For the producer, on the other hand, the "welfare" measure is the change in profits resulting from the change to TOD rates, plus a rate structure adjustment; the "surplus" measure does not include the rate structure effect. The rate structure effect accounts for the change in preferences in moving to TOD rates, which are held constant (i.e., the same as the conventional tariff). The change in profits was estimated using an hourly engineering model.

Strictly from an economic welfare perspective, the correct value of discounted net benefits from moving to TOD rates is $\$ 1.7$ million (excluding metering costs), using the welfare measure for both consumer and producer components. However, the difference between the surplus and welfare measure of consumer effects is negligible, suggesting that changes in consumers' surplus are good proxies for the correct welfare measure (i.e., compensating variation) in cost-benefit studies.

\footnotetext{
${ }^{21}$ The other three utilities in the study were Illinois Power Co., Central Illinois Public Service Co., and Commonwealth Edison. CILCO was singled out arbitrarily; its results are qualitatively the same as the other three utilities.

${ }^{2}$ The results show a best-case TOD rate scenario for CILCO in which the highest net benefits were selected from a range of options: a 4:1, peak:off-peak price ratio; a peak period lasting from 8:00 a.m. to 10 p.m.; and a tariff applicable only to customers with a minimum of $1500 \mathrm{kWh}$ consumption during the peak month of the year which includes 12 percent of all low-voltage customers.
} 
Table 11

Central Illinois Light Company

Comparison of Discounted Net Benefits of TOU Rates"

Different Methodologies

(In Millions of 1982 Dollars)

\begin{tabular}{|c|c|c|c|}
\hline \multirow{2}{*}{$\begin{array}{l}\text { Consumer } \\
\text { Measure }\end{array}$} & \multicolumn{3}{|c|}{ Producer Measure } \\
\hline & Welfare & None & Surplus ${ }^{c}$ \\
\hline Welfare $^{d}$ & $\begin{array}{c}1.7 \\
(-6.1)\end{array}$ & $\begin{array}{c}2.5 \\
(-5.3)\end{array}$ & $\begin{array}{c}0.6 \\
(-7.2)\end{array}$ \\
\hline None & $\begin{array}{c}-0.8 \\
(-8.6)\end{array}$ & $(-)$ & $\begin{array}{c}-1.9 \\
(-9.7)\end{array}$ \\
\hline Surplus ${ }^{e}$ & $\begin{array}{c}1.7 \\
(-6.1)\end{array}$ & $\begin{array}{c}2.5 \\
(-5.3)\end{array}$ & $\begin{array}{c}0.6 \\
(-7.2)\end{array}$ \\
\hline
\end{tabular}

SOURCE: Computed from Caves, Christensen, Schoech, and Hendricks (1984)

'Before metering costs; numbers in parentheses are after metering costs.

${ }^{b}$ Changes in net revenues, plus adjustment for the rate structure effect.

'Changes in net revenues.

'Equivalent variation: change in income that would have same effect on consumers'

utility as change to TOU prices.

'Estimated change in consumers' surplus.

For CILCO, a study considering the change in profits as the sole criterion for the cost-effectiveness of TOD rates (minus $\$ 1.9$ million before metering costs: consumer-none, producer surplus in Table 4), substantially underestimates the net benefits of TOD rates. The discounted net benefits attributable to the rate structure effect and consumer benefits were $\$ 1.1$ million (i.e., $-\$ 0.8$ less $-\$ 1.9$ million) and $\$ 2.5$ million ( $\$ 1.7$ million less $-\$ 0.8$ million), respectively. Thus, the negative $\$ 1.9$ million in discounted net benefits before metering should have been a positive $\$ 1.7$ million, considering all of the effects of TOD rates.

\subsection{INDIVIDUAL TOD TARIFFS}

In contrast to this study integrating supply- and demand-side effects, other studies of the cost-effectiveness of TOD tariffs have examined the rates from the standpoint of the consumer, including only metering costs on the supply side. A sample of these types of studies are presented in Table 12, all of which were based on data from the U.S. residential TOD pricing experiments. The studies were conducted on consumers in different states under varied climatic conditions with different rate structures. The methodologies employed in the analyses also differed. In some, the analyses were conducted separately for different consumption levels; in others, all consumers were aggregated. 
Table 12

Summary of Four Cost-Benefit Studies

U.S. Residential TOD Tariffs

\begin{tabular}{|c|c|c|c|c|}
\hline Utility & Peak & $\begin{array}{l}\text { Consumption } \\
\text { Level }\end{array}$ & $\begin{array}{l}\text { Peak: } \\
\text { Off-Peak }\end{array}$ & Results \\
\hline $\begin{array}{l}\text { Wisconsin Public Service } \\
\text { Southern Ca Edison } \\
\text { Los Angeles Dept of Water } \\
\text { Arizona Public Service }\end{array}$ & $\begin{array}{l}\text { Winter } \\
\text { Summer } \\
\text { Summer } \\
\text { Summer }\end{array}$ & $\begin{array}{l}\text { No } \\
\text { No } \\
\text { Yes } \\
\text { No }\end{array}$ & $\begin{array}{c}2,4,8 \\
2,3 \\
3 \\
\text { Various }\end{array}$ & $\begin{array}{l}8: 1 \text { beneficial } \\
\text { All consumers } \\
1100 \mathrm{kWh}+ \\
\text { Most rates }\end{array}$ \\
\hline
\end{tabular}

SOURCES: Parks and Weitzel (1984), Lillard-Aigner (1984), Acton-Mitchell (1980), and Howrey-Varian (1984), respectively.

In the Lillard-Aigner (Southern California Edison), Howrey-Varian (Arizona Public Service Company), and Acton-Mitchell (Los Angeles Department of Water and Power) studies conducted on utilities whose peak electricity consumption is attributable to a summer air-conditioning load, the results generally show a net benefit from TOD pricing. The LillardAigner and Howrey-Varian studies measured consumer response for a typical consumer, aggregated over consumers with different monthly consumption amounts. The former showed a net benefit to consumers in moving to a 2:1 peak:offpeak tariff, even with a long peak period defined from 10 a.m. to 8 p.m. Howrey-Varian showed that the typical Arizona consumer would benefit by 20 to 30 percent in moving from a current flat rate of $8 \mathrm{c} / \mathrm{KWh}$ to a TOD rate with a 16:5:3 peak:shoulder:off-peak price ratio. The Acton-Mitchell study was noteworthy because it categorized consumers by the actual amount of monthly electricity consumption, allowing utility planners to target specific consumer groups for TOD tariffs. All of the consumer categories defined in the study showed welfare gains (i.e., consumer benefits) in moving from a flat $5 \leftarrow / \mathrm{KWh}$ rate to a $3: 1$, peak:offpeak rate $(9 \leftarrow / \mathrm{KWh}: 3 \leftarrow / \mathrm{KWh})$. However, assuming a $\$ 1.64$ monthly metering charge, the tariff is cost-effective only for consumers with monthly consumption in excess of $1,100 \mathrm{KWh}$. 


\section{EMERGING TECHNOLOGY AND FUTURE DIRECTIONS IN ELECTRICITY PRICING}

Thus far, the discussion has addressed "static" TOU pricing, rate structures that are based on forecasted service costs and, absent a fuel adjustment clause which reduces the time between rate changes, may last six months or as long as one or two years, depending on individual utilities and regulatory authorities. The rates are preset in the sense that they do not change immediately in response to changing conditions on a utility's power delivery system. For any individual utility, however, the cost of supplying electricity varies hour-byhour, day-by-day, and season-by-season, based on conditions that cannot be predicted with precision when static rates are determined.

From the standpoint of supply, electric utilities have long had the ability to determine system operating costs instantaneously. On the demand-side, however, the ability to convey that information to consumers and to monitor electricity consumption over very short time intervals has been limited. Electromechanical meters do not lend themselves well to monitoring electricity consumption by time of use. Emerging communication and metering technologies, however, have proved encouraging for matching current costs of providing electricity service with prices reflecting those costs; rather than based on forecasts of costs, these rates are based on "real time" conditions. ${ }^{23}$

A number of Western utilities have started to exploit these technological advances by experimenting with real time rates, using different technologies and tariff types. In one of the earliest experiments for residential customers in Western Europe, the British Broadcasting Company transmitted real-time electricity prices every five minutes; controlled appliances in English households were in turn shut off electronically when the price exceeded a threshhold level. Under the French Peak Day Withdrawal (PDW) tariff implemented in 1982, the peak day is announced one-half hour in advance, but is limited to only 22 days of the year. Sweden has also adopted a form of RTP targeted at large industries, office and apartment buildings, and users with dual fuels by announcing tariffs (based on water levels) close to the time that they take effect.

In the United States, numerous experiments are under way with various degrees of RTP elements, and the number is growing. For low-voltage users, the most ambitious experiment is at the Georgia Power Company, where four rates are preset, but the hours of the day when they are effective vary. Under the tariff, a four-tier interval rate was developed, ensuring that 40 percent of the time the rate will be $\$ 0.05 / \mathrm{KWh}, 40$ percent of the time it will be $\$ 0.025 / \mathrm{kWi}$, 19 percent of the time it will be $\$ 0.095 / \mathrm{KWh}$, and one percent of the time it will be $\$ 0.18 / \mathrm{KWh}$. Therefore, 80 percent of the time the rate will be under the standard residential rate of $\$ 0.055 / \mathrm{KWh}$. Information on which rating period is in effect is transmitted to consumers via a two-way communications system, largely through the customer's existing telephone and television system.

\footnotetext{
${ }^{23}$ Rates for wholesale or bulk power transactions between utilities or within a power pool have long been based on "real" (hourly) costs. Here, we are discussing end-use sales.
} 
Rather than provide a summary of these experiments, we focus here on the experiments of three U.S. utilities in more detail to highlight the main features of real-time pricing (RTP). ${ }^{24}$ Table 13 summarizes these experiments. The three experiments are similar in that they involve a small number of higher-voltage, commercial and industrial consumers. Pacific Gas and Electric Company (PG\&E) entered into a three-year

Table 13

Design of Three U.S. Real-Time Pricing Experiments

\begin{tabular}{|c|c|c|c|}
\hline Category & PG\&E & $\mathrm{SCE}^{\mathrm{b}}$ & $\mathrm{NMP}^{\mathrm{c}}$ \\
\hline \multicolumn{2}{|c|}{ Sector (Commercial/Industrial) } & $\mathrm{C} / \mathrm{I}$ & $\mathrm{C} / 1$ \\
\hline Customers (Number) & 15 & 10 & 9 \\
\hline Technology & Electronic Mail & Radio & Electronic Mail \\
\hline Rate Variance $(\$ / K W h)$ & $\$ 0.036$ to $\$ 0.507$ & $\$ 0.018$ to $\$ 1.359$ & $\$ 0.016$ to $\$ 0.396$ \\
\hline Notification Period & One Day & One Day & One Day \\
\hline
\end{tabular}

SOURCES: Pacific Gas and Electric Company (1989), Fagan (1989), and Niagra Mohawk Power Corporation (1989).

"Pacific Gas and Electric Company, California

'Southern California Edison Company, California

Niagra Mohawk Power Company, New York

demonstration phase of its RTP experiment in 1988 using electronic mail as the communication medium. ${ }^{25}$ Also using electronic mail for communicating prices, Phase I of the hourly integrated pricing program (HIPP) at Niagra Mohawk Power Corporation (NMP) was initiated in April 1988. After conducting a pre-test of its experiment in 1986, the Southern California Edison Company (SCE) initiated a two-year real-time pricing experiment in 1988. ${ }^{2 \pi}$ In contrast to the experiments of PG\&E and NMP using electronic mail, SCE

\footnotetext{
${ }^{24}$ The interested reader is referred to Tabors, Schweppe, and Caramanis (1988) for an overview of many of the ongoing experiments in the United States.

${ }^{25}$ The RTP experiment began in 1985 with a case study of four customers, proceeding to a pilot phase in 1986 87 with nine commercial/industrial customers participating. These three years laid the groundwork for the demonstration phase in 1988-1990, with anticipated expansion after that time. The 1985-1987 period allowed PGE to fine tune the program, with one of the major changes coming in the transmission technology for prices. The electronic mailing system was found to be more cost-effective and reliable than the prior system of Process System (S-7000) Central Station.

${ }^{26}$ In another experiment, SCE supplemented its "static" TOD tariff with an on-peak incremental rate, which varies in real time, that allows customers who otherwise would terminate operations during peak periods because of high on-peak prices to purchase electricity during the period.
} 
uses an experimental, two-way communications system, Network Communications (NetComm), consisting of a central computer, electronic meters at customer sites, and a network of high-frequency, low-packet radios connecting the two. The radios are mounted on power poles in the distribution system and re ay information from the central computer to individual consumers via service wires which stretch from distribution transformers to homes (Southern California Edison, 1989).

In PG\&E's experiment, participating customers are provided price signals a day in advance on an hourly basis, reflecting PG\&E's hourly short-run marginal (energy) cost and including a fixed demand charge. The tariff is enhanced by a load management price signal (LMPS) effective for a maximum of 50 hours each year, reflecting extreme demand conditions on the system. During 1988, the standard RTP rate varied from $3.6 \$ / \mathrm{KWh}$ during an offpeak hour in March to $10.5 \Phi / \mathrm{KWh}$ during a peak hour in July. The average monthly onpeak rate during months containing peak-hour rates (May through October) were higher than those in the standard, static TOD tariff. With the exception of one month, all RTP rates were higher than the standard TOD tariff during off-peak periods. Finally, rates under the LMPS during the 42 hours it was invoked over the June through. August period varied from nearly $34 \mathrm{\Phi} / \mathrm{KWh}$ during a six-hour period in June to more than $50 \AA / \mathrm{KWh}$ for two five-hour periods in July.

SCE, on the other hand, provides three rate forecasts to better inform its customers of expected conditions on the system: (1) 90 days in advance, (2) on the Monday of the upcoming week, and (3) a 24-hour forecast which most closely reflects the actual costs of electricity. Nine day-types are included in the experiment, reflecting both weather conditions and day of the week (weekday vs. weekend), varying from a "winter weekend day" to an "extremely hot summer weekday." Rates for the former are based on the lower of rejected economy energy or the cost of unused base load energy plus a contribution to margin, while the latter rate is based on the cost of supplying electricity when the system is approaching its capacity limit. During other hours, rates are based on short-run marginal cost with an appropriate revenue adjustment factor. From Table 5, rates on these day-types vary from 1.83 $₫ / \mathrm{KWh}$ on an off-peak weeliend day to $\$ 1.359 / \mathrm{KWh}$ during peak hours on an "extremely hot summer weekday."

In the NMP experiment, the short-run marginal cost-based tariff is forecasted on an hourly basis and transmitted to customers 24 hours in advance of when the tariff goes into effect. The tariff consists of two parts: (1) an energy charge, consisting of the short run marginal cost and an outage cost which is related to a marginal reduction in reliability of the system and (2) a monthly access charge which is a lump sum computed to make each of the experimental customers revenue neutral between the HIPP rate and the standard TOD rate. Of the three experiments, the NMP rates exhibited the least variability; the highest rate during the first year of the experiment was $39.6 / \mathrm{KWh}$ (Table 13).

Because the experiments have been initiated recently, scheduled to be expanded in upcoming years, the results are preliminary and somewhat mixed. Preliminary analysis of customer response in SCE's experiment showed that only two customers significantly reduced load during peak periods. At PG\&E, six customers reduced demand during peak periods, six exhibited little response, and three were mixed. As a whole, the participating customers at PG\&E saved 12 percent of their electricity cosis in comparison with the standard TOD rate, 
with savings ranging from two to 17 percent depending on the customer's ability to respond. In the NMP experiment, response was significant during times when prices were at their highest. For the highest-priced period of the year $(40 \oplus / \mathrm{KWh})$, load was reduced by more than $19 \mathrm{~mW}$ for the 9 customers, more than a 33 percent reduction in load in comparison with a baseline load profile for these customers. In all experiments, response to real-time rates is somewhat similar to that of static TOD rates: the ability to alter production processes on short notice--in this case, a 24-hour warning--deterrnines responsiveness to real-time prices, at least in the short run. Indeed, in PG\&E's marketing of their experiment, it was shown that customers who were not willing to participate in the program expressed the view that they would not be able to shift load on such short notice. 


\section{BIBLIOGRAPHY}

Acton, Jan P., 1982, "An Evaluation of Economists' Influence on Electric Utility Rate Reforms," American Economic Review, 72(2), May, pp. 114-119.

Acton, Jan P. and D. McKay, 1984, Industrial Response to Time-of-Use Rates: Quantitative Analysis of French, English, and Welsh Data, Electric Power Research Institute, Palo Alto, California, EA-3506, May.

Acton, Jan P. and Bridger M. Mitchell, 1980, "Do Time-of-Use Rates Change Load Curves? And How Would You Know?," Public Utilities Fortnightly, 105(15), May 22.

Acton, Jan P. and Bridger M. Mitchell, 1981, "The Effect of Time-of-Use Rates: Facts versus Opinions," Public Utilities Fortnightly, April 23.

Acton, Jan P. and R. Park, 1984, Projecting Response to Time-of-Day Electricity Rates, The Rand Corporation, Pasadena, California, December.

Acton, Jan P. and Rolla E. Park, 1987, Response to Time-of-Day Electricity Rates by Large Business Customers: Reconciling Conflicting Evidence, The RAND Corporation, Santa Monica, California, R-3477-NSF, August.

Aigner, Dennis J., 1984, "The Welfare Econometrics of Peak-Load Pricing for Electricity: Editor's Introduction," Joumal of Econometrics, 26(1/2), September/October.

Aigner, Dennis J., 1985, "The Residential Electricity Time-of-Use Pricing Experiments: What Have We Learned?," in Jerry A. Hausman and David A. Wise, Editors, Social Experimentation, The University of Chicago Press, Chicago, Illinois.

Aigner, Dennis J. and J.G. Hirschberg, 1985, "Commercial/Industrial Customer Response to Time-of-Use Electricity Prices: Some Experimental Results," Rand Journal of Economics, 16(3), Autumn, pp. 341-55.

Aigner, Dennis J. and Edward E. Leamer, 1984, "Estimation of Time-of-Use Pricing Response in the Absence of Experimental Data: An Application of the Methodology of Data Transferability," Journal of Econometrics, 26(1/2), Seplember/October.

Aigner, Dennis J. and L.A. Lillard, 1984, "Measuring Peak Load Pricing Response from Experimental Data: An Exploratory Analysis, "Journal of Business and Economic Statistics, 2(1), January, pp. 21-39.

Andersson, R., 1984, "Electricity Tariffs in Sweden," Energy Economics, 6(2), April, pp. 122 30.

Andersson, R., 1986, "Electricity Tariffs in Sweden--A Reply," Energy' Economics, 8(1), January, pp. 54-56. 
Barrager, S.M. and O.E. Buckley, 1987, Cost-Benefit Analysis of Demand-Side Planning Alternatives, Electric Power Research Institute, Palo Alto, California, EM-5068, February.

Battelie-Columbus and Synergic Resources Corporation, 1984, Demand-Side Management: Volume 1, Overview of Key ,Issues (August); Volume 2, Evaluation of Alternatives (December); and Volume 3, Technology Alternatives and Market Implementation Methods (December), Electric Power Research Institute, Palo Alto, California, EA/EM-3597.

Blevins, R.P. et al., 1987, Demand-Side Management: Volume 4, Commercial Markets and Programs, Electric Power Research Institute, Palo Alto, California, EA/EM-3597, September.

Blevins, R.P. et al., 1988, Demand-Side Management: Volume 5, Industrial Markets and Programs, Electric Power Research Institute, Palo Alto, California, EA/EM-3597, March.

Blevins, R.P. et al., 1987, DSM Technology Alternatives, Electric Power Research Institute, Palo Alto, California, EM-5457, October.

Boggis, J.G., 1973, Domestic Tariffs Experiment, Load and Market Research Report No. 121, The Electricity Council, London, England.

Boiteux, 1960, "Peak Load Pricing," Journal of Business (Originally appeared in Revue Generale de l'electricite, 1949).

Broehl, J.H. et al., 1985, The Demand-Side Management Information Directory, Electric Power Research Institute, Palo Alto, California, EM-4326, December.

Brochl, J.H. et al., 1986, Demand-Side Management for Rural Electric Systems, Electric Power Research Institute, Palo Alto, California, EM-4385, February.

Brown, D.R. and G.E. Spanne, 1989, "Current Cost and Performance Requirements for Residential Cool-Storage Systems," Energy, 14(11).

Bzura, J.J., 1988, "Radio Controll of Water Heaters in Rhode Island," Presented at the IEEE/PES 1988 Summer Meeting, Portland, Oregon, July 24-29.

California Public Utilities Commission and California Energy Commission, 1987, Standard Practice Manual: Economic Analysis of Demand-Side Management Programs, December.

Caves, Douglas W., P. Hanser, Joseph A. Herriges, and Robert J. Windle, 1988, "Load Impact of Interruptible and Curtailable Rate Programs: Evidence from Ten Utilities," IEEE Transactions on Power Systems, 3(4), November.

Caves, Douglas W. and Laurits R. Christensen, 1980, "Residential Substitution of Off-Peak for Peak Electricity Usage Under Time-of-Use Pricing," Energy Journal, 1(2), April. 
Caves, Douglas W., Laurits R. Christensen, and Joseph A. Herriges, 1984a, "Modeling Alternative Residential Peak-Load Electricity Rate Structures," Journal of Econometrics, 24(3), March, pp. 249-68.

Caves, Douglas W., Laurits R. Christensen, and Joseph A. Heriges, 1984b, Consistency of Residential Customer Response in Time-of-Use Electricity Pricing Experiments," Journal of Econometrics, 26(1/2), September/October.

Caves, Douglas W., Laurits R. Christensen, and Joseph A. Herriges, 1984c, Residential Response to Time-of-Use Rates: Volume 1, Development and Dernonstrattion of a Transferability Model; Volume 2, User's Guide to RETOU; and Volume 3, Data and Statistical Appendixes, Electric Power Research Institute, Palo Alto, California, EA-3560, June.

Caves, Douglas W., Laurits R. Christensen, and Joseph A. Herriges, 1987, Residential Response to Time-of-Use Rates: Volume 4, Assessing RETOU's Out-of-Sample Performance, Electric Power Research Institute, Palo Alto, California, EM-3560, March.

Caves, Douglas W., Laurits R. Christensen, Philip E. Schoech, and Wallace Hendricks, 1984, "A Comparison of Different Methodologies in a Case Study of Residential Time-of-Use Electricity Pricing: Cost-Benefit Analysis," Journal of Econometrics, 26(1/2), September/October.

Caves, Douglas W., Joseph A. Herriges, and Kathleen A. Kuester, 1989, "Load Shifting under Voluntary Residential Time-of-Use Rates," Energy Journal, 10(4).

Chan, M.L. and R. Carlson, 1983, Issues in Implementing a Load Management Program for Direct Load Control, Electric Power Research Institute, Palo Alto, California, EA-2904, March.

Chung, Chinbang and Dennis J. Aigner, 1981, "Industrial and Commercial Demand for Electricity by Time-of-Day: A California Case Study," Energy Journal, 2(3), July.

Ciliano, R.E., 1987, Electrotechnologies: Potential for Improving Manufacturing Productivity, Electric Power Research Institute, Palo Alto, California, EM-5259, August.

Davis, T.D., 1988, DSM Residential Customer Acceptance: Volume 1, Planning Insights; Volume 2, Database Guidebook, Electric Power Research Institute, Palo Alto, California, EM-5766, April.

Decision Focus, Inc., 1987, Cost-Benefit Analysis of Demand-Side Planning Alternatives, Electric Power Research Institute, Palo Alto, California, EM-5068, February.

de Voghel, Luk, 1989, "Tariffs used for Load Management in Europe," in Proceedings: International Workshop on Innovative DSM Techniques, Electric Power Research Institute, Palo Alto, California, CU-6332, April. 
Duda, James W., 1988, "The Evolution of Automatic Meter Reading," Public Utilities Fortnightly, June 23.

Ebasco Business Consulting Co., 1985, Innovative Rate Design Survey, Electric Power Research Institute, Palo Alto, California, EA-3830, January.

Ebasco Business Consulting Co., 1988, Innovative Rate Design Survey: 1986, Electric Power Research Institute, Palo Alto, California, EM-5705, March.

Edvinsson, Mats J., 1986, "Load Management in Europe: Marketing Aspects," IEEE Transactions on Power Apparatus and Systems, PWRS-1(4), November.

Edvinsson, Mats J. and Mats O. Nilsson, 1987, "Integrating Load Management with SupplySide Operations: A Case Study," IEEE Transactions on Power Apparatus and Systems, PWRS-2(3), August.

Fagan, Jennifer, 1989, "Real Time Pricing at Southern California Edison Company," in New Dimensions in Electricity Pricing: Proceedings, Electric Power Research Institute, Palo Alto, California, CU-6300, April.

Faruqui, Ahmad and J. Robert Malko, 1983, "The Residential Demand for Electricity by Time-of-Use: A Survey of Twelve Experiments with Peak Load Pricing," Energy, 8(10), pp. 781-95.

Faruqui, Ahmad, Ken Seiden, and Steven D. Braithwait, 1990, "Impaci of Utility DemandSide Management Programs on U.S. Electricity Demand: 1990-2010, " Proceedings ACEEE 1990 Summer Study on Energy Efficiency in Buildings, Volume 5, Integrated Resource Planning, American Council for an Energy-Efficient Economy, Washington, D.C., August.

Flory, John E. and Owen L. Parker, 1985, "Communication and Metering Equipment for Electricity Spot Pricing," PAS-104 IEEE Transactions on Power Apparatus and Systems, (6), pp. 1363-1369, June.

Gallant, A. Ronalr', and Roger W. Koenker, 1984, "Costs and Benefits of Peak-Load Pricing of Electricity: A Continuous Time Econometric Approach," Joumal of Econometrics, 26(1/2), September/October.

Gellings, C.W., J.H. Chamberlin, and J.M. Clinton, 1987, Moving Toward Integrated Resource Planning: Understanding the Theory and Practice of Least-Cost Planning and Demand-Side Management, Electric Power Research Institute, Palo Alto, California, EM-5065, February.

George, S.S. et al., 1988, DSM Commercial Customer Acceptance: Volume 1, Program Planning Insights (January); Volume 2, Suvey and Database Documentation (April), Electric Power Research Institute, Palo Alto, California, EM-5633.

George, S.S. et al., 1988, DSM: Market Research Issues and Methods, Electric Power Research Institute, Palo Alto, California, EM-5632, February. 
Hartman, R.S. and M.J. Doane, 1986, "The Estimation of the Effects of Utility-Sponsored Conservation Programs," Applied Economics, 18(1), January, pp. 1-25.

Hausman, William J. and John L. Neufeld, 1984, "Time-of-Day Pricing in the U.S. Electric Power Industry at the Turn of the Century," The Rand Journal of Economics, 15(1), Spring, pp. 116-126.

Henderson, J.S., 1983, "Costs and Benefits of Residential Time-of-Use Metering: Comment," Energy Journal, 4(1), January, pp. 161-165.

Hill, Daniel H., E.P. Howrey, et al., 1982, Analysis of Residential Response to Time-of-Day Prices, Electric Power Research Institute, Palo Alto, California, EA-2380, May.

Hill, Lawrence J., 1987, Energy Price Reform in Developing Countries: Issues and Options, Oak Ridge National Laboratory, Oak Ridge, Tennessee, ORNL-6391, August.

Hirschberg, J.G. and D.J. Aigner, 1983, "An Analysis of Commercial and Industrial Customer Response to Time-of-Use Rates," Energy Journal, 4, Supplement, pp. 103-26.

Hjalmarsson, L. and A. Veiderpass, 1986, "Electricity Tariffs in Sweden--A Comment," Energy Economics, 8(1), pp. 51-53.

Howrey, E. Philip and Hal R. Varian, 1984, "Estimating the Distributional Impact of Timeof-Day Pricing of Electricity," Journal of Econometrics, 26(1/2), September/October.

Huettner, D.A., J. Kasulis, and N. Dikeman, 1982, "Costs and Benefits of Residential Timeof-Use Metering: Reply," Energy Journal, 3(3), July.

Huettner, D.A., J. Kasulis, and N. Dikeman, 1983, "Costs and Benefits of Residential Timeof-Use Metering: Reply," Energy Journal, 4(1), January, pp. 166-69.

Isaksen, L., 1987, Survey of Utility Lighting Programs, Electric Power Research Institute, Palo Alto, California, EM-5093, February.

Jones, I.S., 1985, "Distortions in Electricity Pricing in the U.K.: A Comment," Oxford Bulletin of Economics and Statistics, 47(3), August, pp. 275-285.

Jones, Donald and Garland Samuels, 1988, Enengy Requirements of Development Projects, Oak Ridge National Laboratory, Oak Ridge, Tennessee, ORNL-6298, January.

Keane, Dennis M. and Andrew Goett, 1988, "Voluntary Residential Time-of-Use Rates: Lessons Learned from Pacific Gas and Electric Company's Experiment," IEEE Transactions on Power Systems, 3(4), November.

Keelin, Thomas W. and Clark W. Gellings, 1986, Impact of Demand-Side Management on Future Customer Electricity Demand, Electric Power Research Institute, Palo Alto, California, EM-4815-SR, Octobur. 
Kohler, Daniel F. and Bridger M. Mitchell, 1984, "Response to Residential Time-of-Use Electricity Rates: How Transferable are the Findings," Journal of Econometrics, 26(1/2), September/October.

Lee, K.K., C.A. Clayton, and D.T. Boutilier, 1981, Time-of-Use Electricity Price Effects: Los Angeles, Research Triangle Institute, Research Triangle Park, North Carolina, July.

Lee, K.K., A.K. Miedema, D.P. Lifson, and M.S. Kumm, 1981, Time-of-Use Electricity Price Effects: Wisconsin, Research Triangle Institute, Research Triangle Park, North Carolina, August.

Lescoeur, B. and J.B. Galland, 1987, "Tariffs and Load Management: The French Experience," PWRS-2 IEEE Transactions on Power Systems, (2), pp. 458-464, May.

Levy, Roger D., 1985, Control Strategies for Load Management, Electric Power Research Institute, Palo Alto, California, EM-3882, July.

Lillard, Lee A., 1987, Variable-Response Model of Electricity Demand by Time of Day: Results of a Wisconsin Pricing Experiment, Electriv Power Research Institute, Palo Alto, California, EM-5194, June.

Lillard, Lee A. and Dennis J. Aigner, 1984, "Time-of-Day Electricity Consumption Response to Temperature and the Ownership of Air Conditioning Appliances," Journal of Business and Economic Statistics, 2(1), January, pp. 40-53.

Manning, Willard, Bridger M. Mitchell, and Jan P. Acton, 1979, "Design of the Los Angeles Peak-Load Pricing Experiment for Electricity," Journal of Econometrics, 2(1), September, pp. 131-94.

McDonald, C., 1985, Demand-Side Planning: Sierra Pacific Power Company Case Study, Electric Power Research Institute, Palo Alto, California, EM-5567, January.

McFate, KL. and J. Skelton, 1988, Residential, Commercial, and Agricultural Technology Alternatives for Rural Electric Systems, Electric Power Research Institute, Palo Alto, California, EM-5567, January.

Miedema, Allen K., Kay K. Lee, and S.B. White, 1981. Time-of-Use Electricity Price Effects, Final Report, Research Triangle Institute, Research Triangle Park, North Carolina, November.

Miederna, A.K., K.M. Stern, and K.H. Lee, 1985, Commercial and Industrial Response to Time-of-Use Rates: Methodology and Case Studies, Electric Power Research Institute, Palo Alto, California, EM-4206, August.

Miedema, A. K., S.B. White, C.A. Clayton, B.V. Alexander, and M.S. Kumm, 1981, Time-ofUse Eltectricity Price Effects: North Carolina, Research Triangle Institute, Research Triangle Park, North Carolina, May. 
Mitchell, B., W. Manning, and J. Acton, 1978, Peak Load Pricing: European Lessons for U.S. Energy Policies, Ballinger Publishing Co., Cambridge, Massachusetts.

Nemetz, Peter N. and Marilyn Hankey, 1984, Economic Incentives for Energy Conservation, John Wiley \& Sons, New York.

Niagra Mohawk Power Corporation, 1989, Hourly Integrated Pricing Program: Annual Report, Syracuse, New York.

Noell, Sharon K, 1989, "Incentives for Residential Direct Load Control," in New Dimensions in Electricity Pricing: Proceedings, Electric Power Research Institute, Palo Alto, California, CU-6300, April.

Oak Ridge National Laboratory, 1982, Utility-Controlled Customer-Side Thermal Energy Storage Tests: Heat Storage, Oak Ridge, Tennessee, ORNL-5796, February.

Oak Ridge National Laboratory, 1983, Utility-Controlled Customer-Side Thermal Energy Storage Tests: Cool Storage, Oak Ridge, Tennessee, ORNL-5795, February.

Pacific Gas and Electric Company, 1989, Demand-Side Real Time Pricing: 1988 Annual Report, San Francisco, California.

Park, Rolla E. and Jan P. Acton, 1984, "Large Business Customer Response to Time-of-Day Electricity Rates," Joumal of Econometrics, 26(1/2), September/October.

Parks, Richard W., 1983, Energy Use and Customer Welfare Effects of Residential Time-of-Use Rates, Electric Power Research Institute, Palo Alto, California, EA-2832, January.

Parks, Richard W. and David Weitzel, 1984, "Measuring the Consumer Welfare Effects of Time-Differentiated Electricity Prices, "Joumal of Econometrics, 26/1/2), September/October.

Parks, T., 1988, Home Automation Technology Directory, Electric Power Research Institute, Palo Alto, California, EM-5699, March.

Patton, A.D. and C. Singh, 1984, Study of Effect of Load Management on GeneratingSystem Reliability, Electric Power Research Institute, Palo Alto, California, EA-3575, July.

Peddie, R.A., 1983, "A Credit and Load Management System: Design Considerations," IEEE Transactions on Power Apparatus and Systems, PAS-102(8), August.

Peddie, R.A., 1983, "Customer/Utility Relationships: A New Approach to Credit and Load Management Systems," IEEE Transactions on Power Apparatus and Systems, PAS-102(8), August. 
Peddie, R.A., G. Frewer, and A. Goulcher, 1983, The Application of Economic Theory Utilizing New Technology for the Benefit of the Consumer, South Eastern Electricity Board, London.

Procter, R.J. and W.E. Tyner, 1.384, "Assessing the Impact of Peak-Load Electricity Pricing and the Solar Tax Credits on the Adoption of Solar Energy," Land Economics, 60(1), February, pp. 49-55.

Reddoch, Thomas, 1987, "Requirements for Implementing Real-Time Pricing," Presented at the IEEE/PES 1987 Summer Meeting.

Rosenfeld, Arthur H., Douglas A. Bulleit, and Robert A. Peddie, 1986, "Smart Meters and Spot Pricing: Experiments and Potential," IEEE Technology and Society Magazine, pp. 23 28, March.

Sanghvi, Arun P., 1988, "Flexible Strategies for Load/Demand Management Using Dynamic Pricing, IEEE Transactions on Power Systems, Forthcoming.

Sanghvi, Arun P., 1988, Towards a More Efficient Framework for Rationalizing Power Tariffs," Pacific and Asian Joumal of Energy, Forthcoming.

Schweppe, Fred C., Michael C. Caraminis, Richard D. Tabors, and R. Bohn, 1988, Spot Pricing of Electricity, Kluwer Press.

Slater, M.D.E. and G.K. Yarrow, 1983, "Distortions in Electricity Pricing in the U.K.," Oxford Bulletin of Economics and Statistics, 45(4), November, pp. 317-38.

Slater, M.D.E. and G.K. Yarrow, 1985, "Distortions in Electricity Pricing in the U.K.: Reply," Oxford Bulletin of Econornics and Statistics, 47(3), August, pp. 287-91.

Southern California Edison Co., 1989, Research Newsletter, Rosemead, California, March.

Steiner, Peter O., 1957, "Peak Loads and Efficient Pricing," Quarterly Journal of Economics, November.

Stickels, T.D. and L.C. Markel, 1987, Residential Load Contro! and Metering Equipment: Costs and Capabilities, Electric Power Research Institute, Palo Alto, California, EM-5392, October.

Strickler, Gary F. and Sharon K. Noell, 1988, "Residential Air Conditioner Cycling: A Case Study, ${ }^{n}$ IEEE Transactions on Power Systems, 3(1), February.

Tabors, R.D., F.C. Schweppe, and M.C. Caramanis, 1988, "Utility Experience with Real Time Rates," Presented at the IEEE/PES 1988 Summer Meeting, Portland, Oregon, July 24-29.

Taylor, T.N. and P.M. Schwarz, 1986, "Residential Demand Charge: Evidence from the Duke Power Time-of-Day Pricing Experiment," Enengy Joumal, 7(2), April, pp. 135-51. 
Tishler, A., 1983, "The Industrial and Commercial Demand for Electricity under Time-of-Use Pricing," Journal of Econometrics, 23(3), December, pp. 369-84.

Train, K.E., D.L. McFadden, and A.A. Goett, 1987, "Consumer Attitudes and Voluntary Rate Schedules for Public Utilities," Review of Economics and Statistics, 69(3), August, pp. 38391.

U.S. Agency for International Development, 1988, Power Shortages in Developing Countries: Magnitude, Impacts, Solutions, and the Role of the Private Sector, Washington, D.C., March.

Veall, M.R., 1986, "Time-of-Use Rates and Peak Period Electricity Consumption: An Empirical Note," Energy Economics, 8(4), October, pp. 257-62.

Wenders, John T. and Lester D. Taylor, 1976, "Experiments in Seasonal Time-of-Day Pricing of Electricity to Residential Users," Bell Joumal of Economics, 7 (Autumn), pp. 531-552.

Woo, C.-K, 1984, "A Note on Measuring Household Welfare Effects of Time-of-Use (TOU) Pricing," Energy Journal, 5(3), July, pp. 170-81.

Woo, C.-K, 1985, "An Application of the Expenditure Function in Electricity Pricing: Optimal Residential Time-of-Use Rate Option," Energy Joumal, 6(2), April, pp. 89-99.

Woo, Chi-Keung, 1985, "Demand for Electricity of Small Nonresidential Customers under Time-of-Use (TOU) Pricing, The Energy Journal, 6(4).

Woo, C.-K. and N. Toyama, 1986, "Service Reliability and the Optimal Interruptible Rate Option in Residential Electricity Pricing," Energy Journal, 7(3), July. 

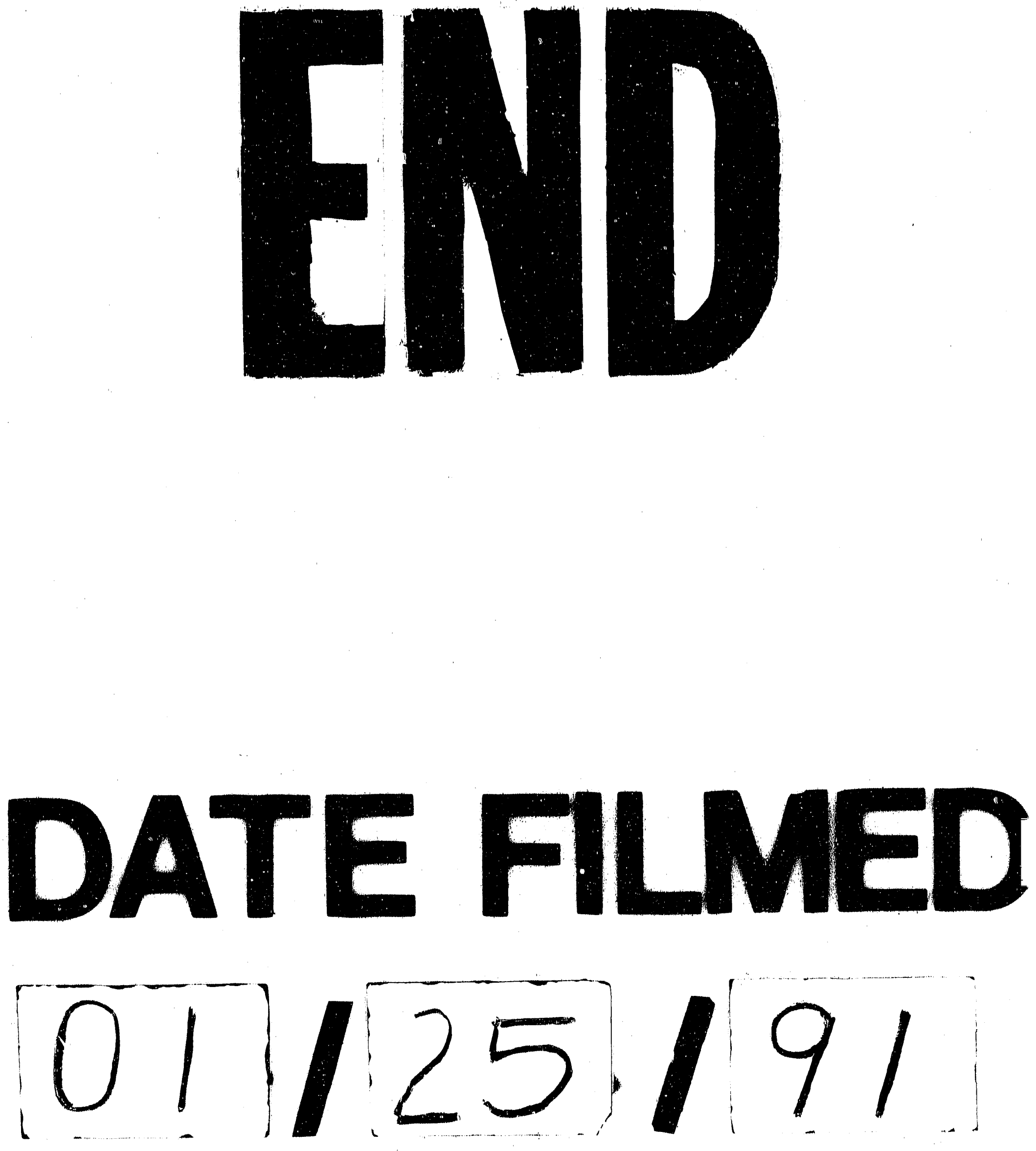
